\title{
An Annotated Bibliography of Computer Supported Cooperative Work
}

\author{
Saul Greenberg
}

1991

Cite as:

Greenberg, S. (1991) "An annotated bibliography of computer supported cooperative work." ACM SIGCHI Bulletin, 23(3), pp. 29-62. July. Reprinted in Greenberg, S. ed. (1991)

"Computer Supported Cooperative Work and Groupware, pp. 359-413, Academic Press. 


\title{
An Annotated Bibliography of Computer Supported Cooperative Work
}

\author{
Saul Greenberg \\ Department of Computer Science, University of Calgary \\ Calgary, Alberta, Canada T2N 1N4 \\ phone: (403) 220-6087 \\ email:saul@cpsc.ucalgary.ca
}

\begin{abstract}
Computer-supported cooperative work (CSCW) is a new multi-disciplinary field with roots in many disciplines. Due to the area's youth and diversity, few specialized books or journals are available, and articles are scattered amongst diverse journals, proceedings and technical reports. Building a CSCW reference library is particularly demanding, for it is difficult for the new researcher to discover relevant documents. To aid this task, this article compiles, lists and annotates some of the current research in computer supported cooperative work into a bibliography. Over 300 references are included.
\end{abstract}

\section{Introduction}

An important part of any new research venture is building and maintaining a reference collection of relevant publications. This article provides a bibliography of computer supported cooperative work (CSCW). Many entries are annotated with a brief description derived from snippets from the original abstract, my personal notes, and from commentaries written by other people. Annotations also include a keyword list for topic disambiguation, where each keyword is selected from the limited set shown in Table 1. The article also includes and overview of the general sources that publish CSCW works (Section 2 ), and a list of groupware systems and concepts indexed to the bibliography (Section 3).

The bibliography is available in both an EndNote ${ }^{1}$ database and a Refer database. Those wishing an electronic version of this bibliography can obtain it in two ways. The EndNote database and a Microsoft word copy of this document are available by writing the author at the above address (please enclose a 3.5 inch Macintosh disc and a self-addressed stamped envelope). The Refer database and other related files are available via anonymous ftp from cpsc.ucalgary.ca in the directory pub/CSCWbibliography.

\section{General CSCW Sources}

\footnotetext{
1 EndNote is a Macintosh-based bibliographic package available through Niles \& Associates Inc.
}

Due to the youth and diversity of CSCW, there are only a handful of specialized books available. Most of the literature is scattered amongst many journals, proceedings of conferences and workshops, and technical reports. This section is a resource guide for readers interested in tracking the relevant published literature in CSCW and groupware ${ }^{2}$.

Books. Perhaps the best selection of CSCW articles is provided by Irene Greif's “Computer Supported Cooperative Work" (Greif, 1988) ${ }^{3}$. Her collected readings span from the earliest visions of CSCW to present day theory and practice. On the groupware front, Johansen's “Groupware: Computer support for business teams" is a very readable layman's book detailing current approaches and applications of groupware to business environments (Johansen, 1988). Two recent CSCW collections cover social and technological support for work group collaborations: "Intellectual teamwork" by Galegher, Kraut and Egido (1990); and "Technological support for work group collaboration” by Olson (1989). "Computer supported cooperative work and Groupware" (Greenberg, 1991c) collects 16 CSCW articles previously published in a 2-part special

\footnotetext{
${ }^{2}$ With special thanks to Jonathan Grudin, who provided a contents list of several books and proceedings, and where selected articles had been republished.

${ }^{3}$ The annotated references to books and proceedings include a list of section or conference session names and, in some cases, ordering information.
} 
edition of the International Journal of Man Machine Studies, as well as this bibliography.

Conferences. The major conference for CSCW is the bi-annual ACM-sponsored "Conference on Computer-Supported Cooperative Work". The first conference was held in 1986 in Austin, Texas (ACM Press, 1986). Although its proceedings are no longer in publication, many of the articles have been reprinted in revised form in the books and journals mentioned in this section. Proceedings of the 1988 Portland Oregon conference and the 1990 Los Angeles California conference (ACM Press, 1988 \& 1990) are available from the ACM Order Department, PO Box 64145, Baltimore, MD, USA 21264. These proceedings are of excellent quality, with collected papers covering most contemporary work.

The "European Community Conference on Computer Supported Cooperative Work" is the European counterpart to the ACM conference. The first was held on September 13-15 in Gatwick, London, UK (EC-CSCW, 1989), with a second scheduled for fall of 1991 in Amsterdam, The Netherlands. Proceedings are available from the Computer Sciences Company, Computer Sciences House, Brunel Way, Slough, United Kingdom SL1 1XL.

Several other important conferences deserve mention. The "IFIP WG8.4 Conference on Multi-User Interfaces and Applications" was recently held in Crete (Gibbs and Verrijn-Stuart, 1990). The "Symposium on Computer Conferencing", once centered around distance education and asynchronous conferencing, now has broader coverage more in line with CSCW (University Of Guelph, 1987 and 1990). ACM's "SIGCHI Conference on Human Factors in Computing Systems" and the "SIGOIS Conference on Office Information Systems" normally have special sessions, panels or papers on CSCW.

Journals. There are no dedicated journals for CSCW. Still, the ones listed below do publish occasional papers of interest.

ACM Transactions on Information Systems has had several special editions on CSCW. These tend to republish selected and revised papers previously presented at the ACM-sponsored CSCW conferences. In particular, see Volumes 5(2) 1987, and 6(3\&4) 1988. A forthcoming edition will feature several articles from the CSCW'90 conference.

The International Journal of Man Machine Studies has formalized its interest in CSCW in its reorganization of the editorial board into topic areas, one being CSCW. A two-volume special edition on CSCW and Groupware containing sixteen new articles on a variety of topics was published in February/March of 1991. Academic Press has republished this collection as a book (Greenberg, 1991c).

The December 1988 issue of Byte had a special section devoted to CSCW papers, and the odd highquality article has appeared in Communications of the ACM and IEEE Computer. ACM's SIGCHI Bulletin and SIGOIS Bulletin occasionally contain relevant articles and summaries of conferences and workshops. Other mainstream human-computer interface and management-oriented journals also have the odd article on CSCW. These include Behaviour and Information Technology; Decision Support Systems; Human Computer Interaction; Interacting with Computers; Management Science; and Office: Technology and People.

\section{Major collections included in the bibliography.}

The bibliography contains a large mix of references. While some come from from the "gray literature" of unusual journals, research reports, and unpublished papers, most come from the sources listed above. The following list shows which major collections of CSCW papers are completely included in this bibliography.

- Proceedings of the 1986, 1988, and 1990 ACM Conference on Computer Supported Cooperative Work (ACM Press: 1986, 1988 \& 1990)

- Proceedings of the 1989 European Community Conference on Computer Supported Cooperative Work (EC-CSCW, 1989)

- Proceedings of the 1990 IFIP WG8.4 Conference on Multi-User Interfaces and Applications (Gibbs and Verrijn-Stuart, 1990)

- Computer supported cooperative work and groupware (Greenberg, 1991c)

- Intellectual teamwork: Social and technical foundations of cooperative work (Galegher, Kraut and Egido, 1990)

- Computer Supported Cooperative Work: A book of readings (Greif, 1988)

- Technological Support for Work Group Collaboration (Olson, 1989)

- International Journal of Man Machine Studies Special Editions on CSCW and Groupware (February and March 1991), republished in Greenberg (1991c)

- ACM Transactions on Information Systems Special Editions on CSCW vol 5(2) 1987; 6(3) and 6(4) 1988 


\section{Index to Groupware Systems and CSCW concepts}

\begin{tabular}{|c|c|}
\hline Name & Citation \\
\hline $\begin{array}{l}\text { ACE (Amsterdam Conversation } \\
\text { Environment) }\end{array}$ & Dykstra 1991 \\
\hline AMIGO model & Danielsen 1986 \\
\hline Andrew Messaging System & Borenstein $1988 \mathrm{a}, 1988 \mathrm{~b} \& 1991$ \\
\hline Animating Interfaces & Wulff 1990 \\
\hline Aplex project & Bodker 1988 \\
\hline ArgNoter & Stefik 1987a \& 1987b \\
\hline Audio windows & Cohen 1991 \\
\hline Augment/NLS & Engelbart 1963, 1968, 1982, 1984, 1988 \& 1990 \\
\hline Banyan & Jackson 1989 \\
\hline BITNET & Jarrell 1986; Pliskin 1989 \\
\hline BoardNoter & Stefik 1987a \& 1987b \\
\hline Callisto & Sathi 1986 \\
\hline$C A V E C A T$ & Mantei 1991 \\
\hline Cantata & Chang 1986, 1987a \& 1989 \\
\hline Capture Lab & EDS 1988; Halonen 1989; Losada 1990; Mantei 1988 \& 1989 \\
\hline CATeam Room & Ferwanger 1989; Lewe 1990 \\
\hline CHAOS & De Cindio 1986 \\
\hline ClearFace & Ishii 1991 \\
\hline CoAuthor & Hahn 1989 \\
\hline Cognoter & Foster 1986; Stefik 1987a \& 1987b; Tatar 1991 \\
\hline CoLab & Foster 1986; Stefik 1987a \& 1987b; Tatar 1991 \\
\hline Collaboratory & Lederberg 1989 \\
\hline Commune & Bly 1990; Minneman 1990 \& 1991; Tang 1990 \\
\hline Confer & Fanning 1986 \\
\hline Contexts & Delisle 1987 \\
\hline Cookbook & Ishii 1990b \\
\hline Coordination theory & Malone 1988 \& 1990 \\
\hline Coordinator & Bair 1988; Erickson 1989; Winograd 1986, 1988a \& 1988b \\
\hline Cosmos & Bowres 1988 \\
\hline Cruiser & Fish 1989; Root 1988 \\
\hline $\begin{array}{l}\text { DHSS Large Demonstrator } \\
\text { Project }\end{array}$ & Storrs 1989 \\
\hline Dialogo & Lantz 1986 \& 1989; Lauwers 1990a \& 1990b \\
\hline Diamond & see $M M C O N F$ \\
\hline DistEdit & Knister 1990 \\
\hline Earth Lab & Newman 1988 \\
\hline Electronic Brainstorming System & Applegate 1986 \\
\hline Envisioning Machine & Singer 1988 \\
\hline $\begin{array}{l}\text { EuroPARC Multi-media } \\
\text { Environment }\end{array}$ & Moran 1990; Buxton 1990 \\
\hline gIBIS & (see also rIBIS) Conklin 1988; Lee 1990a; Yakemovic 1990 \\
\hline GroupSketch & Greenberg 1990 \\
\hline Grove & Ellis $1988 \mathrm{a} \& 1988 \mathrm{~b}$ \\
\hline Hypermate & Ellis $1988 b$ \\
\hline ICICLE & Brothers 1990 \\
\hline Intermedia & Garrett 1986; Landow 1990 \\
\hline InVision & Kass 1989 \\
\hline$K M S$ & Yoder 1989 \\
\hline Liveware & Witten 1991 \\
\hline Liza & Ellis 1988b; Gibbs 1989 \\
\hline$M A F I A$ & Lutz 1990 \\
\hline MBlink & Sarin 1985 \\
\hline Mermaid & Watabe 1990 \\
\hline
\end{tabular}


Name

\begin{tabular}{|c|c|}
\hline Name & Citation \\
\hline MIAC conferencing system & Clark 1989 \\
\hline$M M C O N F$ & Crowley 1987, 1989 \& 1990; Lison 1989; Thomas 1985 \\
\hline Mosaic & Garcia-Luna-Aceves 1988 \\
\hline NETLIB & Dongarra 1987 \\
\hline Notecards & Halasz 1988; Trigg 1986 \& 1988 \\
\hline NSF EXPRES & Olson 1990 \\
\hline Object Lens, Information Lens & $\begin{array}{l}\text { Crowston 1988b; Lia 1988; Mackay } 1989 \text { \& 1990; Malone 1986, 1987, } \\
\text { 1987a \& 1989; Tarazi } 1989\end{array}$ \\
\hline Office design project (Xerox) & Harrison 1989; Stults 1988 \\
\hline Open Hyperdocument System & Engelbart 1990 \\
\hline$P A G E S$ & Mantyla 1990 \\
\hline Portland Experiment & Abel 1990a; Goodman 1987b; Olson 1991 \\
\hline PREP editor & Neuwirth 1990 \\
\hline Project Nick & Begeman 1986; Cook 1987; Ellis 1988b; Rein 1989 \\
\hline Quilt & Leland 1988 \\
\hline RandMail & Eveland 1987 \\
\hline Rapport & Ahuja 1990; Ensor 1988 \& 1989 \\
\hline Rendezvous & Patterson 1990 \\
\hline rIBIS & Rein 1991 \\
\hline RTCal & Sarin 1985 \\
\hline SharedARK & Smith $1988 \& 1989$ \\
\hline SharedX & Garfinkel 1989; Gust 1988 \& 1989 \\
\hline Share & Greenberg 1990b \& 1990c \\
\hline$S I B Y L$ & Lee $1990 \mathrm{a}$ \\
\hline Simple Simon's GesturePad & Gerrissen $1990 b$ \\
\hline Slate $(B B N)$ & See MMConf \\
\hline Speech filing system & Gould 1983 \& 1984 \\
\hline STRUDEL & Shepherd 1990 \\
\hline SYNVIEW & Lowe 1986 \\
\hline Talking Heads & MIT 1983a \\
\hline TeamWorkstation & Ishii 1990a, 1990c, 1991, 1991 (submitted) \\
\hline Timbuktu & Farallon 1988; Guttman 1989 \\
\hline Together & Quinn 1990 \\
\hline Trillium & Blomberg 1986 \\
\hline University of Arizona GDSS & Valacich 1991; Vogel 1990 \\
\hline Unix customization files & Mackay 1990 \\
\hline $\begin{array}{l}\text { US West Tele-collaboration } \\
\text { Project }\end{array}$ & Abel 1990b; Bulick 1989; Corey 1989 \\
\hline VideoDraw & Tang $1989 \& 1990$ \\
\hline VideoWhiteboard & Tang 1991 \\
\hline VideoWindow & Fish 1990 \\
\hline Video wall (Xerox) & See Portland Experiment \\
\hline Virtual Environments & Cohen 1991 \\
\hline Visual Schedular & Beard 1990 \\
\hline Vmacs & Lakin 1990 \\
\hline XSketch & Lee $1990 b$ \\
\hline
\end{tabular}

Citation 


\begin{tabular}{|c|c|}
\hline Keyword & Meaning \\
\hline $\begin{array}{l}\text { asynchronous } \\
\text { conferencing }\end{array}$ & $\begin{array}{l}\text { Different time, different place meetings. Also known as computer-mediated } \\
\text { communication, computer conferencing, and bulletin boards }\end{array}$ \\
\hline collection & A collection of papers, readings, essays, etc \\
\hline conceptual & High-level discussion of CSCW \\
\hline critique & General analysis and assessment of CSCW \\
\hline data sharing & Sharing of common data (files, etc) \\
\hline decision support & Group decision support systems (GDSS) \\
\hline education & CSCW applied to education \\
\hline email & Electronic mail \\
\hline evaluation & $\begin{array}{l}\text { A formal study by controlled experiment, questionairre, field study, } \\
\text { observations, etc }\end{array}$ \\
\hline face-to-face meetings & Meetings in the same place and at the same time \\
\hline hypertext & Hypertext and Hypermedia \\
\hline idea processors & Idea processors, outliners, brainstorming tools \\
\hline implementation & A description of an implemented system or a commercially available product \\
\hline informal meetings & $\begin{array}{l}\text { Explicit recognition of informal encounters and meetings, and technical } \\
\text { support of them }\end{array}$ \\
\hline multimedia & Multiple types of media (graphics, voice, video, text, rasters, etc) \\
\hline organizational concerns & Organizational issues in the use/acceptance of groupware \\
\hline overview & An overview/survey of an area within CSCW \\
\hline participatory design & $\begin{array}{l}\text { Users are involved as part of the design team. Article describes how to do it, or } \\
\text { describes tools supporting it, or discusses implications to CSCW. }\end{array}$ \\
\hline protocols & Person to person communication protocols such as speech acts \\
\hline remote meetings & Meetings held at the same time, different location \\
\hline report & Report on a workshop or conference \\
\hline semi-structured messages & Template-based textual communication with some free text \\
\hline shared views & Shared views and serial interaction with single-user systems \\
\hline shared workspace & Shared workspaces, usually supporting simultaneous participant activity \\
\hline social impact & Social science theory and social issues in the use of CSCW systems \\
\hline software design & $\begin{array}{l}\text { Design and development of groupware including both design process and } \\
\text { toolkits }\end{array}$ \\
\hline video & Video is used as a component of the CSCW system or for data analysis \\
\hline virtual environments & Shared virtual environments or ideas related to it \\
\hline virtual hallways & Social real-time interaction in a virtual world \\
\hline
\end{tabular}

Table 1: Keywords used to annotate the bibliography entries and their meanings

\section{Bibliography}

Abel, M. (1990a) "Experiences in an exploratory distributed organization." In Intellectual Teamwork: Social Foundations of Cooperative Work, p489-510, J. Galegher, R. E. Kraut and C. Egido ed., Hillsdale, New Jersey, Lawrence Erlbaum Associates. (virtual hallways, video, informal meetings, evaluation) Abel describes a case study of a video wall used to create permanent links between two geographically-distributed research labs to support informal interaction. The system is described as adequate (but just barely so) for creating a joint sense of place and culture.

Abel, M., Corey, D., Bulick, S., Schmidt, J. and Coffin, S. (1990b) "The US West Advanced Technologies TeleCollaboration research project." In Computer Augmented Teamwork, G. Wagner ed.Van Nostrand Reinhold.

(virtual hallways, video, informal meetings) This chapter provides an overview of the US West TeleCollaboration project. The emphasis is on supporting day-to-day interaction among individuals, especially informal, spontaneous interaction. Motivation, technical infrastructure, and lessons learnt are provided. A good sequel to Xerox's Portland experiment. 
Abel, M. J. and Rein, G. L. (1989) "Report on the collaborative technology developers' workshop." SIGCHI Bulletin, 20(3), p86-89, January. Also published in ACM SIGOIS 1989 10(1). (report, software design) This brief report summarizes the 1988 CSCW workshop held for developers building collaborative technologies. Several issues were raised: 1) personalized views versus what you see is what I see (WYSIWIS); 2) synchronous versus asynchronous interaction; 3) navigation and visual metaphors; 4) single vs multi-user applications; 5) social protocols and the niche for sociologists. The workshop was part of the CSCW '88 conference.

ACM Press (ed.) (1986) "Proceedings of the 1986 Conference on Computer Supported Cooperative Work." ACM Press. December 3-5, Austin, Texas. (collection) Session titles were: 1 Supporting faceto-face groups; 2 Empirical studies; 3 Supporting distributed groups; 4 Hypertext systems; 5 Underlying technology for collaborative groups; 6 Collaboration research; 7 Interfaces: Multimedia and multi-user; 8 Industrial experience with computersupported groups; 9 Coordination and decisionmaking. Although proceedings are no longer available, many of the articles have been reprinted/revised in: Trans Office Information Systems 1987 5(2) and 1988 6(3); Human-Computer Interaction 3(1); Office: Technology and People 1987 3; Computing Surveys 1988 20(2); and Greif (1988).

ACM Press (ed.) (1988) "Proceedings of the 1988 Conference on Computer Supported Cooperative Work." ACM Press. September 26-28, Portland, Oregon.

(collection) Session titles were: 1 Remote communication; 2 Work settings and applications; 3 Perspectives on evaluation; 4 Structured communication technologies; 5 Practical experiences in system development; 6 Enabling technologies and environments; 7 Synchronous communication; 8 Collaborative learning; 9 Electronic mail; 10 Perspectives. A few articles have been revised/reprinted in: Trans Office Information Systems 1988 6(4); Office: Techonology and People 1989 4(2) and 4(3). Proceedings available from ACM Order Department, PO Box 64145, Baltimore, MD 21264, or phone 1-800-342-6626.

ACM Press (ed.) (1990) "Proceedings of the 1990 Conference on Computer Supported Cooperative Work." ACM Press. October 7-10, Los Angeles, California.

(collection) Session titles were: 1 Shared video spaces; 2 Experimental studies in CSCW; 3 Supporting structured communication; $4 \mathrm{CSCW}$ within and across organizations; 5 Cooperative support and customization; 6 User interfaces in the CSCW context; 7 (CS)CW in the field; 8 Systems infrastructure for $\mathrm{CSCW}$; 9 Issues and perspectives on CSCW. Proceedings available from ACM Order Department, PO Box 64145, Baltimore, MD 21264, or phone 1-800-342-6626.
Adrianson, L. and Hjelmquist, E. (1988) “Group processes in face-to-face and computer-mediated communication." Department of Psychology, University of Gotenborg.

(evaluation, decision support, face-to-face meetings, remote meetings, protocols) This study reports results from an experiment investigating different aspects of communication pattern and communicative outcome. The experiment was a $2 \times 2 \times 2$ ANOVA. Factors were mode of communication (face-to-face vs computer mediated), problem type (human relation vs technical ranking problem) and experience (experienced vs inexperienced). Results show no differences in decision quality depending upon medium, but more consensus decisions in face-toface. No equalization of participants was seen in computer-mediated communication, contrary to previous research.

Ahuja, S. R., Ensor, J. R. and Lucco, S. E. (1990) "A comparison of applications sharing mechanisms in real-time desktop conferencing systems." In Proceedings of the Conference on Office Information Systems, p238-248, Boston, April 25-27.

(shared views, software design, implementation) This paper contrasts three architecturally different versions of a shared window system (Rapport): a single-site centralized approach, a multi-site distributed approach, and a combination of the two. Performance issues were discussed, and the single-site approach was recommended.

Allen, R. B. (1990) "User models: Theory, method, practice.” Int J Man Machine Studies, 32(5), p511-544, May.

(asynchronous conferencing) This paper describes the use of user models to select and filter information sources for readers of information services. Results suggest that prediction of preferences are straightforward for general categories of news articles, but difficult when specific news reports are desired.

Ancona, D. G. and Caldwell, D. F. (1990) "Information technology and work groups: The case of new product teams." In Intellectual Teamwork: Social Foundations of Cooperative Work, p173-190, J. Galegher, R. E. Kraut and C. Egido ed., Hillsdale, New Jersey, Lawrence Erlbaum Associates.

(organizational concerns, social impact) The focus is on groups which face the highly interactive and complex task of developing new products. A description is presented of the activities in which these teams engage, and moves from that data to suggest how information technology might better be used to support the work of those teams. The work is premised on the belief that an in-depth understanding of the group's complex tasks is necessary to realize the full capabilities of technology.

Applegate, L. M., Konsynski, B. R. and Nunamaker, J. F. (1986) “A group decision support system for idea generation and issue analysis in organizational planning." In Proceedings of the Conference on 
Computer Supported Cooperative Work, p16-34, Austin, Texas, December 3-5, ACM Press. (decision support, idea processors, face to face, evaluation) The idea generation and management process has been chosen as the domain for the study of the design and implementation of a GDSS to support complex, unstructured group decision processes within organizations. Results of research conducted in the MIS Planning and Decision Laboratory on the use of the Electronic Brainstorming System with over 100 planners are presented. Planners reported high levels of satisfaction with the process and rated the computer brainstorming tool as much better than manual brainstorming.

Attewell, P. and Rule, J. (1984) "Computing and organizations: What we know and what we don't know." Comm ACM, 27(12), p1184-1192. Reprinted in Greif, 1988.

(organizational concerns) This paper analyses the earlier literature on the effects of computing in organizations. The literature is found to be inconsistent and inconclusive.

Austin, L. C., Liker, J. K. and McLeod, P. L. (1990) "Determinants and patterns of control over technology in a computerized meeting room." In Proceedings of the Conference on Computer Supported Cooperative Work (CSCW'90), p3952, Los Angeles, California, October 7-10, ACM Press.

(face-to-face meetings, evaluation) Groups completed a priorization task in a "low structure" computerized meeting room. All group members had equal access to a public screen used to complete the task. The authors studied how groups distributed control of the technology, the determinants of which group members took control, and the consequences of control. They noticed that proficiency with the computer interface and the social influence are factors which predicted who will take control. Dedicated versus non-dedicated scribes are also discussed.

Bair, J. H. (1987) "CSCW '86." ACM SIGOIS Bulletin, 8(3), p3-13. (report) A review of the CSCW '86 conference.

Bair, J. H. (1989) "Supporting cooperative work with computers: Addressing meeting mania." In Proceedings of the 34th IEEE Computer Society International Conference-CompCon Spring, p208217, San Francisco, CA, February 27-March 3. (overview, face-to-face meetings, critique) This paper argues that $\mathrm{CSCW}$ is a renewed recognition of user needs for extensions to current communication media. A taxonomy of communication media is provided; four levels of user needs---informing, coordinating, collaborating and cooperating---are presented; limits of current media are raised; and extensions of electronic media are proposed. A good overview of the area, its problems, and directions to follow.

Bair, J. H. and Gale, S. (1988) "An investigation of the Coordinator as an example of computer supported cooperative work." Hewlett Packard Laboratories, California. Unpublished.

(semi-structured messages, protocols, critique, evaluation) This paper describes an extensive investigation of the Coordinator and the suitability of speech-act systems in organizations. Conclusions and recommendations are included.

Bannon, L., Bjorn-Andersen, N. and Due-Thomsen, B. (1988) "Computer support for cooperative work: An appraisal and critique." In Eurinfo '88. Information Systems for Organizational Effectiveness, H. J. Bullinger ed., Amsterdam, North-Holland. (critique)

Bannon, L. J. and Schmidt, K. (1989) "CSCW: Four characters in search of a context." In Proceedings of the 1st European Conference on Computer Supported Cooperative Work (EC-CSCW'89), p358-372, Gatwick, U.K., September 13-15, Computer Sciences House, Sloug, UK. (conceptual, critique) This paper highlights the inadequacies of the CSCW acronym. A framework for approaching the issue of cooperative work and computer support is provided; core issues are identified; and the fields prospects are outlined.

Beard, D., Palanappian, M., Humm, A., Banks, D. and Nair, A. (1990) "A visual calendar for scheduling group meetings." In Proceedings of the Conference on Computer Supported Cooperative Work (CSCW'90), Los Angeles, California, October 7-10, ACM Press.

(face-to-face meetings, evaluation, organizational concerns) This paper discusses a comprehensive group meeting scheduling system called "Visual Schedular" that summarizes available information for quick, flexible, and reliable scheduling. A controlled experiment shows the automated system to be faster and less error-prone than manual scheduling, and a field study shows the Visual Schedular to be generally useful. An interesting paper, as it contradicts previous studies that suggested that automated scheduling systems do not work in practice.

Beaudouin-Lafon, M. (1990) "Collaborative development of software." In Proceedings of IFIP WG8.4 Conference on Multi-User Interfaces and Applications, Crete, S. Gibbs and A. A. VerrighnStuart (ed), North Holland.

Begeman, M., Cook, P., Ellis, C., Graf, M., Rein, G. and Smith, T. (1986) "Project NICK: Meetings augmentation and analysis." In Proceedings of the Conference on Computer-Supported Cooperative Work (CSCW '86), p1-6, Austin, Texas, December 3-5, ACM Press.

(face-to-face meetings) See Cook (1987) for an expanded version of this paper.

Benford, S. (1989) "Requirements of activity management." In Proceedings of the 1st European Conference on Computer Supported Cooperative Work (EC-CSCW'89), Gatwick, U.K., September 13-15, Computer Sciences House, Sloug, UK. 
Benson, I., Ciborra, C. and Proffitt, S. (1990) "Some social and economic consequences of groupware for flight crew." In Proceedings of the Conference on Computer Supported Cooperative Work (CSCW '90), Los Angeles, California, October 710, ACM Press.

(organizational concerns, evaluation) Groupware can never substitute for the social and organisational integration of team members, but it can fill many of the inevitable logistical, knowledge and communication gaps that always arise, especially in large and/or dispersed teams performing complex tasks. Within this context, a case study of 3000 flight crew from a major European airline is described.

Berlin, L. M. and O'Day, V. L. (1990) "Platform and application issues in multi-user hypertext." In Proceedings of IFIP WG8.4 Conference on MultiUser Interfaces and Applications, Crete, S. Gibbs and A. A. Verrighn-Stuart (ed), North Holland.

Bermann, T. and Thorenson, K. (1988) "Can networks make an organization?" In Proceedings of the Conference on Computer-Supported Cooperative Work (CSCW '88), p153-166, Portland, Oregon, September 26-28, ACM Press. (participatory design, evaluation, organizational concerns, social impact) The authors share their experience of a cooperative systems development project involving centralization of several previously independent surgical departments in a hospital. A few simple cases illustrate that the conventional development process is wrought with conflicts, contradictions and challenges. In particular, the design of a cooperative system can neither be pushed by technology, nor by the workers view of what they require. Rather, the process is collaborative, where both designer and end user forward and evaluate ideas during system development. The work is an example of the "Scandinavian approach" to design.

Bhandaru, N. and Croft, B. (1990) "Architecture for supporting goal-based cooperative work." In Proceedings of IFIP WG8.4 Conference on MultiUser Interfaces and Applications, Crete, S. Gibbs and A. A. Verrighn-Stuart (ed), North Holland.

Bignoli, C. and Simone, C. (1989) "AI techniques for supporting human to human communication in CHAOS." In Proceedings of the 1st European Conference on Computer Supported Cooperative Work (EC-CSCW '89), Gatwick, U.K., September 13-15, Computer Sciences House, Sloug, UK.

Bikson, T. K. and Eveland, J. D. (1990) "The interplay of work group structures.” In Intellectual Teamwork: Social Foundations of Cooperative Work, p245-290, J. Galegher, R. E. Kraut and C. Egido ed., Hillsdale, New Jersey, Lawrence Erlbaum Associates.

(email, asynchronous conferencing, evaluation) The paper reports a field experiment using email and computer conferencing to support a task force writing retirement policy. The study shows that computerbased communication can empower otherwise isolated people by providing them with the resources need to accomplish their tasks, including access to information and other people. Barriers to social interaction are reduced, and leadership roles broadened.

Bjerknes, G. and Bratteteig, T. (1988) "The memoirs of two survivors: Or the evaluation of a computer system for cooperative work." In Proceedings of the Conference on Computer-Supported Cooperative Work (CSCW'88), p167-177, Portland, Oregon, September 26-28, ACM Press. (participatory design, evaluation, organizational concerns) The authors describe their experiences with the "ultimate test" of a CSCW system built according to the Scandinavian approach by evaluating its use several months after installation. Through a series of flashbacks of diary clips and analysis, they bring us through the design process, giving the reader insight as to what happened and why things were designed a certain way. The result of their ultimate test did more than show a system in active use, for it described several surprising work habits that had developed.

Blomberg, J. (1986) "The variable impact of computer technologies on the organization of work activities." In Proceedings of the Conference on Computer-Supported Cooperative Work (CSCW '86), p35-42, Austin, Texas, December 35 , ACM Press. Republished in revised form in Greif, 1988.

(organizational concerns, software design, participatory design) New computer tools are affecting the ways in which work is accomplished and, in turn, existing patterns of social interaction are shaping the evolution of these highly malleable tools. This paper explores the interplay between a computer-based design environment employed in the creation of machine interfaces and the "users" of this tool, including the user interface designers and the software engineers supporting the technology. The use of this has resulted in the restructuring of the social organization of the design tasks. An ethnographic study of a computer-based design environment called Trillium is used as an example.

Bly, S. (1988) "A use of drawing surfaces in different collaborative settings." In Proceedings of the Conference on Computer-Supported Cooperative Work (CSCW '88), p250-256, Portland, Oregon, September 26-28, ACM Press.

(shared workspace, evaluation, video) Bly observed designers communicating through three different media: face to face; over a video link that included a view of the other person and their drawing surface; and over the telephone. From her observations, she hypothesizes that the actions, uses, and interactions on a drawing artifact are as important to the effectiveness of many design collaborations as viewing the final artifact. Also, allowing designers to share drawing space activities increases their attention and involvement in the design task. When interaction over the drawing surface is reduced, the quality of the collaboration decreases. 
Bly, S. A. and Minneman, S. L. (1990) "Commune: A shared drawing surface." In Proceedings of the Conference on Office Information Systems, p184192, Boston, April 25-27.

(shared workspace, evaluation, remote meetings) The authors describe Commune, a shared drawing surface, and their observations of two-person use. Commune stresses people's ability not only to make marks simultaneously on the workspace, but to use cursors to support gesturing.

Bodker, S., Ehn, P., Knudsen, J., Kyng, M. and Madsen, K. (1988) "Computer support for cooperative design (invited paper)." In Proceedings of the Conference on Computer-Supported Cooperative Work (CSCW'88), p377-394, Portland, Oregon, September 26-28, ACM Press. (participatory design, social impact, critique) The authors outline their theoretical perspective on design as cooperative work, and exemplifies the approach with reflections from the Aplex project. Historical roots of the Scandinavian approach to design are covered, and critical reflections made.

Bodker, S. and Gronbaek, K. (1991) "Cooperative prototyping: Users and designers in mutual activity." Int J Man Machine Studies, 34(3), p453-478, March. In the special edition on CSCW \& Groupware. Republished in Greenberg, 1991c. (participatory design) Given an environment conducive to participatory design, how does one go about doing it? The authors describe one method called cooperative prototyping. These involve sessions where users experience the future use situation, and then participate with designers in modifying the prototypes when usage breakdowns required it. Their article is especially valuable as it provides a theoretical framework, a practical guide for managing cooperative prototyping sessions, and an example of how cooperative prototyping develops in a real situation.

Bodker, S. and Gronboek, K. (1989) “Cooperative prototyping experiments: Users and designers envision a dental case record system." In Proceedings of the 1st European Conference on Computer Supported Cooperative Work (ECCSCW '89), Gatwick, U.K., September 13-15, Computer Sciences House, Sloug, UK.

Bonfiglio, A., Malatesa, G. and Tisato, F. (1989)

"Conference Toolkit: A framework for real-time conferencing." In Proceedings of the 1st European Conference on Computer Supported Cooperative Work (EC-CSCW'89), Gatwick, U.K., September 13-15, Computer Sciences House, Sloug, UK.

Borenstein, N., Everhart, C., Rosenberg, J. and Stoller, A. (1988a) "A multi-media message system for Andrew." In Proceedings of the USENIX Winter Conference, p37-42, Dallas, Texas, February 9-12. (multimedia, asynchronous conferencing, email) The Andrew Messaging System supports multi-media messages, which may include line-drawings, hierarchical drawings, spreadsheets, rasters, animations, and equations. It is explicitly designed to support a huge database of messages and an enormous user community. It also supports advanced features such as voting, private bulletin boards, shared mailboxes, and automatic classification of incoming mail. It is easily ported, can have multiple interfaces, and is distributed.

Borenstein, N. S. and Thyberg, C. A. (1991) "Power, ease of use, and cooperative work in a practical multimedia message system." Int J Man Machine Studies, 34(2), p229-260, February. In the special edition on CSCW \& Groupware. Republished in Greenberg, 1991.

(asynchronous conferencing, multimedia, implementation, evaluation) The Andrew Message System (AMS) is a powerful multimedia mail and bulletin board system. This paper discusses two parts of AMS. First, advanced features of the Messages program---a high-end interface to AMS---are described, emphasising how it facilitates types of cooperative work that are not possible with other less powerful systems. Second, the Andrew Adviser system is provided as an example way that AMS can help solve problems of distributed support for a very diverse user community.

Borenstein, N. S. and Thyberg, C. A. (1991) "Power, ease of use, and cooperative work in a practical multimedia message system." Int J Man Machine Studies, February. In the special edition on CSCW \& Groupware.

(asynchronous conferencing, multimedia, implementation, evaluation) The Andrew Message System (AMS) is a powerful multimedia mail and bulletin board system. This paper discusses two parts of AMS. First, advanced features of the Messages program---a high-end interface to AMS---are described, emphasising how it facilitates types of cooperative work that are not possible with other less powerful systems. Second, the Andrew Adviser system is provided as an example way that AMS can help solve problems of distributed support for a very diverse user community.

Borning, A. (1991) "Two approaches to casual interaction over computer and video networks." In ACM SIGCHI Conference on Human Factors in Computing Systems, New Orleans, April 28-May 2, ACM Press.

(casual interaction, video)

Bowres, J. and Churcher, J. (1988) "Local and global structuring of computer medicated communication: Developing linguistic perspectives on CSCW in Cosmos." In Proceedings of the Conference on Computer-Supported Cooperative Work (CSCW '88), p125-139, Portland, Oregon, September 2628, ACM Press.

(protocols) This paper is concerned with the development of a language/action perspective in the Cosmos project. The authors emphasise the importance of seeing cooperative work in terms of participant's communicative actions as embedded in dialogical contexts. 
Brandt, R., Depke, D. A., Lewis, G., Hammonds, K. and Hawkins, C. (1989) "The personal computer finds its missing link.” Business Week, p120-128, June 5 .

(overview) This is a popular press article on networking, with some discussion of groupware.

Brothers, L., Sembugamoorthy, V. and Muller, M. (1990) "ICICLE: groupware for code inspection." In Proceedings of the Conference on Computer Supported Cooperative Work (CSCW'90), Los Angeles, California, October 7-10, ACM Press. (face-to-face meetings, shared views, shared workspace) ICICLE (Intelligent Code Inspection Environment in a C Language Environment) is a system intended to augment the process of formal code inspection. While it offers assistance in a variety of activities, the paper is directed towards the groupware issues encountered. ICICLE code inspection occurs within a face to face environment, where a view of the code is displayed on everyone's screen. Readers of the code can have synchronized shared views, or can choose to scroll independently through different parts of the code. Textual comments can be created, shown, and acted upon by participants.

Bulick, S., Abel, M., Corey, D., Schmidt, J. and Coffin, S. (1989) "The US West Advanced Technologies prototype multimedia communication system." In Proceedings of the IEEE Global Telecommunications Conference (GlobeCom), p1221-1226, November. (virtual hallways, video, informal meetings) This is another paper that provides an overview of the US West Telecollaboration project. The most prominant feature is the way video is used to link two remote laboratories.

Bullen, C. V. and Bennett, J. L. (1990a) "Groupware in practice: An interpretation of work experience." Research report CISR WP 205, Sloan WP No. 3146-90, Center for Information Systems Research, MIT, Cambridge, Mass., March. (evaluation, email) This study of 223 people using groupware systems offers an early examination of how people are using personal computers for electronic exchanges via networking. The paper concludes that complex interactions of social and technical factors affect the use of groupware systems in organizations. Issues for developers and managers of groupware systems are raised.

Bullen, C. V. and Bennett, J. L. (1990b) "Learning from user experience with groupware." In Proceedings of the Conference on Computer Supported Cooperative Work (CSCW'90), Los Angeles, California, October 7-10, ACM Press. (email, asynchronous conferencing, organizational concerns, evaluation) This study examines how people are using personal computers for electronic exchanges that link people into task-oriented teams. Conclusions are presented in two ways: from a design perspective, which offers findings which designers of groupware systems to consider; and from an organizational perspective, whose findings should be considered by managers when planning for and implementing groupware systems.

Bush, V. (1945) "As we may think." Atlantic Monthly, 176(1), p101-108, June. Reprinted in Greif, 1988.

(conceptual, hypertext, data sharing) This early paper is considered *the* seminal article for both CSCW and hypertext. Bush describes his vision of the microfilm-based "Memex," a way of structuring and leaving trails through a large, shared information store.

Buxton, B. and Moran, T. (1990) "EuroPARC's Integrated Interactive Intermedia Facility (IIIF): Early experiences." In Proceedings of IFIP WG8.4 Conference on Multi-User Interfaces and Applications, Crete, S. Gibbs and A. A. VerrighnStuart (ed), North Holland.

(virtual hallways, video, informal meetings) This paper describes the EuroPARC "Media Space" setup.

Caldwell, R. G., Van Nest, W. D., Tynan, A. A. and Leach, R. A. (1987) "Conferencing selection and implementation: University of Arizona case history." In The Second Guelph Symposium on Computer Conferencing, p209-222, Guelph, Ontario, Canada, June 1-4, University of Guelph. (asynchronous conferencing, organizational concerns) This paper summarizes the University of Arizona's selection and implementation of an asynchronous conferencing system. The selection criteria and the implementation plan are reviewed. A checklist for successful implementation is provided. The paper is useful for seeing a large organization's strategy for bringing in a conferencing system.

Cashman, P. and Stroll, D. (1987) "Achieving sustainable complexity through information technology: Theory and practice." Office: Technology and People, 3. An earlier version appeared in CSCW '86.

This paper describes a theoretical framework which sheds some light on the relationships between the levels of complexity with which managers deal, the value of information at each level, and the resulting information system requirements. A real-life experiment is described that uses advanced information technology to support strategic business unit management within a large corporation.

Chalfonte, B. (1991) "Expressive richness: A comparison of speech and text as media for revision." In ACM SIGCHI Conference on Human Factors in Computing Systems, New Orleans, April 28-May 2, ACM Press.

Chang, E. (1986) "Participant systems." Future Computing Systems, 1(3), p253-270. (protocols, remote meetings, data sharing, implementation) This paper presents the paradigm of Participant Systems that supports collaborative intellectual tasks among a number of persons, possibly distributed in different locations. To do so, it must support communications, multiple views, common data, common action and common cognitive space. Such a system must coordinate access to a common problem representation, and contain 
sufficient knowledge and expertise in the problem domain to integrate the activity of the users, and even to participate as one of the experts. The Cantata implementation is briefly described.

Chang, E. (1989) "Protocols for group coordination in participant systems." In The Structure of Multimodal Dialogue, p229-247, M. M. Taylor, F. Neel and D. G. Bouwhuis ed., North-Holland, Elsevier Science Publishers B.V.

(remote meetings, protocols) This paper describes the notion of participant systems; the experiences gained with Cantata; and briefly describes related work by other people.

Chang, E., Kasperski, R. and Copping, T. (1987a)

"Group coordination in participant systems." Department of Advanced Computing and Engineering, Alberta Research Council, Calgary, Alberta, Canada. Unpublished.

(protocols, remote meetings, data sharing, implementation) This paper introduces the paradigm of Participant Systems. It describes the Cantata participant system in detail: a) the shared terminal; b) the multi-person real-time text messaging system; c) the shared blackboard; and d) the participant construct system. It lists Cantata's features and how physically distributed groups that operate in real time are supported.

Chang, S. K. and Leung, L. (1987b) "A KnowledgeBased Message Management System.” ACM Trans Office Information Systems, 5(3), p213236, July. (email, implementation) The design approach of a knowledge-based message management system is described. A linguistic message filter is used to filter out junk messages. Relevant messages are then processed by an expert system, driven by user-defined alerter rules. An alerter rule base for a secretarial office is illustrated.

Chapanis, A. (1975) "Interactive human communication." Scientific American, 232(3), p36-42. Reprinted in Greif, 1988. (evaluation, remote conferencing, video) Chapanis describes an important empirical study on the channels and modes through which people converse: voice, handwriting, typewriting, video, and their combinations. The results suggest that while voice and text gives substantial improvement to communication over text alone, adding video gives only a minor improvement.

Ciborra, C. and Olson, M. H. (1988) "Encountering electronic work groups: A transaction costs perspective." In Proceedings of the Conference on Computer-Supported Cooperative Work (CSCW '88), p94-101, Portland, Oregon, September 2628, ACM Press.

(organizational concerns) The goal of this paper is to investigate the organizational context of cooperative work through the transaction cost approach. Implications for system and organizational design are provided.

Cicourel, A. V. (1990) "The integration of distributed knowledge.” In Intellectual Teamwork: Social
Foundations of Cooperative Work, J. Galegher, R. E. Kraut and C. Egido ed., Hillsdale, New Jersey, Lawrence Erlbaum Associates.

(social impact) The paper discusses the importance of coupling information to its source. In collaborative medical diagnosis, the diagnosis arises out of social interaction as physicians exchange observations. Because physicians learn to assess the value of medical information on the basis of its association with a trusted human source, information systems designed to aid medical decision making must somehow incorporate evidence of their own credibility.

Clark, W. J. (1989) "The MIAC audiographic conferencing system: A practical implementation of the audiovisual service infrastructure." In Multimedia '89: Proceedings of the 2nd International Workshop on Multimedia Communications, Montebello, Quebec, April 2023.

(remote meetings, multimedia, implementation) The authors discuss the layout and implementation of the MIAC remote conferencing system.

Clement, A. (1990) "Cooperative support for computer work: A social perspective on the empowering of end users." In Proceedings of the Conference on Computer Supported Cooperative Work (CSCW'90), Los Angeles, California, October 7-10, ACM Press.

(organizational concerns, evaluation) This paper explores the question of empowerment through computerization by looking at common problems of computer use in the context of office group work. In particular it examines the difficulties that secretaries confront when attempting to master desktop computing and the cooperative solutions they have developed to overcome them. Based on the findings, the paper outlines proposals for the design and implementation of CSCW applications intended to enhance the power of clerks and secretaries, office workers who are relatively resource-weak.

Clement, A. and Gotlieb, C. C. (1987) "Evolution of an organization interface: The new business department at a large insurance firm." In Proceedings of the ACM SIGCHI+GI Human Factors in Computing Systems, Toronto, Canada, April 5-9. Reprinted in Greif, 1988.

(organizational concerns) This study looks at the interaction dynamics between a work and a computer organization in a large life-insurance firm. The dynamics of the interaction between the two is explained in terms of "the economic incentive to reduce the length of transaction processing chains and the more political goal of extending managerial control."

Cohen, M. and Ludwig, L. F. (1991) "Multidimensional audio window management." Int J Man Machine Studies, 34(3), p319-336, March. In the special edition on CSCW \& Groupware. Republished in Greenberg, 1991. (virtual environments, remote meetings, implementation) Recent developments in interactive 
Virtual Environments has sparked interest in spatially-located three-dimensional sound. Cohen and Ludwig describe an audio management system called audio windows that integrates spatial sound, audio emphasis, and gestural input recognition. While this exciting use of computer-controlled sound can be applied to any aspect of the human computer interface, the article suggests new enhancements this technology can bring to tele-conferencing.

Conklin, J. (1987) "Hypertext: An introduction and survey." IEEE Computer, 20(9), p17-41. Reprinted in Greif, 1988.

(hypertext) An excellent introduction and survey to hypertext systems. Features of many implementations are contrasted.

Conklin, J. (1988) "gIBIS: A hypertext tool for exploratory policy discussion." In Proceedings of the Conference on Computer-Supported Cooperative Work (CSCW'88), p140-152, Portland, Oregon, September 26-28, ACM Press. (semi-structured messages, protocols, decision support, hypertext) This paper introduces gIBIS, a hypertext system that captures early design deliberations on large complex problems. It is based upon the Issue Based Information Design (IBIS) methodology that views design as a rhetorical process, with a set of issues that can be generalized, specialized, responded to, questioned, argued and so on. gIBIS is based to a large part on semi-structured messages. Participants propose and respond to issues in structured ways that eliminate unconstructive moves such as name-calling and argument by repetition. The authors also evaluate and criticize their work based upon preliminary observations of its use.

Cornell, P. and Luchetti, R. (1989) "Ergonomic and environmental aspects of computer supported cooperative work." In Human Factors Society 33rd Annual Meeting, p862-866.

Cook, P., Ellis, C., Graf, M., Rein, G. and Smith, T. (1987) "Project NICK: Meetings augmentation and analysis." ACM Trans Office Information Systems, 5(2), p132-146, April.

(face-to-face meetings) This paper investigates meetings for the early part of some design process. Face-to-face meetings are an important activity since they provide a medium for direction, exploration, and consensus building. Project Nick is attempting to apply automated facilities to the process, conduct, and semantic capture of the design meetings. Primary topics covered are meeting analysis, meeting augmentation, and a model of meeting progression. The overview (including references) is good. The meeting tool itself deserves a better description.

Cook, S. and Birch, G. (1991) "Modelling groupware in the electronic office." Int J Man Machine Studies, 34(3), p369-394, March. In the special edition on CSCW \& Groupware. Republished in Greenberg, 1991.

(implementation, remote meetings) This is a report on a project to explore ideas for a distributed system that: enhances convenient and effective communication; gives information about each other's status and whereabouts; supports people in planning and execution of various kinds of office tasks. Architectural and user interface issues are discussed.

Corey, D., Abel, M., Bulick, S. and Schmidt, J. (1989) "Multi-media communication: The US WEST advanced technologies prototype system." In Fifth IEEE Workshop on Telematics, Denver, Colorado, September 17-21. Submitted paper. (informal meetings, virtual hallways, video) This paper describes the US WEST virtual hallways system, a fairly elaborate video connection between two distance-separated sites.

Crowley, T., Baker, E., Forsdick, H., Milazzo, P. and Tomlinson, R. (1990) "MMConf: An infrastructure for building shared applications." In Proceedings of the Conference on Computer Supported Cooperative Work (CSCW'90), Los Angeles, California, October 7-10, ACM Press. (shared views, shared workspace, implementation) This paper describes MMConf, a system supporting computer teleconferencing and the way it has been used to support shared applications.

Crowley, T., Forsdick, H., Landau, M. and Travers, V. (1987) "The Diamond Multimedia Editor." In Proceedings of the Summer Usenix 1987 Conference.

(multimedia) This paper describes the Multimedia editor behind the Diamond Multimedia conferencing system.

Crowley, T. and Forsdick, T. (1989) "MMConf: The Diamond Multimedia Conferencing System.” In Groupware Technology Workshop, Palo Alto, California, August.

(remote meetings, shared views, implementation) This paper describes implementation details of the Diamond Multimedia conferencing system, a replicated shared-view system. It includes floor control, all the conference primitives, a telepointer, recording a conference for playback, and its existing packages. Disadvantages and advantages of the replicated architecture are raised.

Crowston, K., Malone, T. and Lin, F. (1988a) "Cognitive science and organizational design: A case study of computer conferencing." Human Computer Interaction, 3(1), p59-85. Reprinted in Greif, 1988. An earlier version was published in CSCW '86.

(organizational concerns, evaluation) The authors characterize information processing in terms of the kinds of messages people exchange. This method is used to analyze the introduction of a computer conferencing system to an organization.

Crowston, K. and Malone, T. W. (1988b) "Intelligent software agents.” Byte Magazine, p267-271, December.

(semi-structured messages, email, asynchronous conferencing) This is a popular introduction to Malone's Object Lens and how it differs from his earlier Information Lens system. A list of other groupware systems that use AI techniques is provided. 
Culnan, M. J. and Bair, J. H. (1983) "Human communication needs and organizational productivity: The potential impact of office automation." Journal of the American Society for Information Science, 34(3), p215-221. (conceptual, social impact) This article defines communication, identifies the potential benefits to be realized from implementing office automation, and offers caveats related to the implementation of office automation systems. Realization of the benefits of office automation depends upon the degree to which new modes of communication may be successfully substituted for traditional modes.

Danielsen, T., Pankoke-Babatz, U., Prinz, W., Patel, A., Pays, P., Smalland, K. and Speth, R. (1986) "The Amigo project: Advanced group communication model for computer-based communications environment." In Proceedings of the Conference on Computer-Supported Cooperative Work (CSCW'86), p115-142, Austin, Texas, December 3-5, ACM Press. (asynchronous conferencing) This paper discusses and elaborates on the conceptual requirements as well as the tools of the General AMIGO Model for group communication. Features of the model are examined with particular reference to the social and ethical implications in the communication process. Applicability of the model is demonstrated by examples.

De Cindio, F., De Michelis, F., Simone, C., Vassallo, R. and Zanaboni, A. (1986) "CHAOS as a coordination technology." In Proceedings of the Conference on Computer-Supported Cooperative Work (CSCW '86), p325-342, Austin, Texas, December 3-5, ACM Press.

(protocols) Cooperation, to the extent that it is made up of communication and coordination, can be fully characterized under the assumption that an office is a special linguistic game, constituted by a set of rules defining the conversations possible within it, continuously changing under the perturbation created by the speech acts its members do performing the conversation. Within this context, the CHAOS prototype aims both at supporting the conversations and at improving coordination of the office activity.

De Koven, C. and Radhakrishnan, T. (1990) "An experiment in distributed group problem solving." In Proceedings of IFIP WG8.4 Conference on Multi-User Interfaces and Applications, Crete, S. Gibbs and A. A. Verrighn-Stuart (ed), North Holland.

Delisle, N. and Schwartz, M. (1987) "Contexts: A partitioning concept for hypertext." ACM Trans Office Information Systems, 5(2). An earlier version appeared in CSCW '86.

(hypertext) A hypertext system makes a good information management system for a software development environment. However, existing hypertext systems provide poor support for collaboration among members of the development teams. Authors examine several modes for forming partitions in a hypertext database and define a notion of "contexts", a partitioning scheme that supports multi-person cooperative efforts.

DeSanctis, G. and Gallupe, R. B. (1987) “A Foundation for the Study of Group Decision Support Systems." Management Science, 33(5), p589-609, May.

(decision support, overview) This paper presents a conceptual overview of group decision support systems based on an information-exchange perspective of decision making. Three levels of systems are described, representing varying degrees of intervention into the decision process.

Dewan, P. (1991) "Flexible user interface coupling in collaborative systems." In ACM SIGCHI Conference on Human Factors in Computing Systems, New Orleans, April 28-May 2, ACM Press.

(remote meetings, evaluation) An important issue in collaborative systems is the kind of sharing or coupling among the various windows displaying a shared workspace (ie how and which components of the windows are shared across people). The paper describes an architecture to an interface toolkit supporting shared views that allows designers to express the degree of coupling between the interface components.

Dollimore, J. and Wilbur, S. (1989) "Experiences in building a configurable CSCW system." In Proceedings of the 1st European Conference on Computer Supported Cooperative Work (ECCSCW '89), Gatwick, U.K., September 13-15, Computer Sciences House, Sloug, UK.

Dollimore, J. R. T. and Coulouris, G. (1990) "Towards a language for defining structure in message-based cooperative work." In Proceedings of IFIP WG8.4 Conference on Multi-User Interfaces and Applications, Crete, S. Gibbs and A. A. Verrighn-Stuart (ed), North Holland.

Dongarra, J. J. and Grosse, E. (1987) "Distribution of Mathematical Software Via Electronic Mail.” Comm ACM, 30(5), p403-407, May. (email, data sharing, implementation) This paper describes how distributed researchers can search for and retrieve items from a network library through NETLIB, a distribution system that handles requests made to it across an electronic mail system.

Dykstra, E. A. and Carasik, R. P. (1991) "Structure and support in cooperative environments: The Amsterdam Conversation Environment." Int J Man Machine Studies, 34(3), p419-434, March. In the special edition on CSCW \& Groupware. Republished in Greenberg, 1991.

(social impact, software design) Dykstra argues that while systems should nourish conversation and stimulate interaction amongst group participants, they should not directly regulate the actual meeting process. Instead, the technology should be supple enough to allow the group itself to define its own (perhaps changing) conventions, structures, and constraints. Several iterations of the Amsterdam 
Conversation Environment, a system supporting groupware as context, are described.

EC-CSCW (ed.) (1989) "Proceedings of the 1st Europeon Conference on Computer Supported Cooperative Work." , Brunel Way, Slough, UK, SL1 1XL, Computer Sciences Company, Computer Sciences House. Conference took place September 13-15 at Gatwick, London, U.K. (collection) Session titles were: 1 Human sciences and empirical methods; 2 Applications; 3 Organisational issues in CSCW; 4 Underlying technologies; 5 General issues in CSCW. Proceedings available from Pam Knibb, Conference Secretariat at the above address.

EDS (1988) "The Capture lab.” EDS Centre for Machine Intelligence, Ann Arbour, Michigan. Videotape.

(face to face meetings, shared views) A video of what is perhaps the best-realized (but incredibly expensive) architecture for a face to face conferencing room---the Capture Lab.

Egido, C. (1988) "Video conferencing as a technology to support group work: A review of its failures." In Proceedings of the Conference on ComputerSupported Cooperative Work (CSCW'88), p1324, Portland, Oregon, September 26-28, ACM Press.

(video, organizational concerns, remote meetings) There are only about 100 video conferencing (VC) sites world-wide, a figure that falls far short of the expected promise. Egido gives two main reasons for this failure. First, vendors gave VC an ill-conceived image as a replacement for face to face meetings. Second, VC is based on inadequate needs assessment methodologies. Most formal interactions are not suitable for video conferencing, and travel is not reduced. Rather, Egido notices that VC actually increases the physical face-to-face meetings, and argues that it is best viewed as a supplement, rather than a replacement of the normal meeting process.

Egido, C. (1990) "Teleconferencing as a technology to support cooperative work: Its possibilities and limitations." In Intellectual Teamwork: Social Foundations of Cooperative Work, p351-372, J. Galegher, R. E. Kraut and C. Egido ed., Hillsdale, New Jersey, Lawrence Erlbaum Associates. (remote meetings, video, evaluation) This paper covers the pitfalls of teleconferencing and video conferencing by reviewing and analyzing existing literature. A spectrum of situations are identified where video conferencing succeeds, offers little, or outright fails.

Ellis, C. (1989) “CSCW '88 report." ACM/SIGOIS Bulletin, 10(1), p2-4, January.

(report) A brief trip report of the 1988 ACM Conference on Computer-Supported Cooperative Work, held in Portland.

Ellis, C. A., Gibbs, S. J. and Rein, G. L. (1991) "Groupware: Some issues and experiences." Comm ACM, 34(1), p38-58, January. (overview) A good overview of current CSCW.
Ellis, C., Gibbs, S. J. and Rein, G. (1988a) "Design and use of a group editor." Technical report STP263-88, MCC, Austin, Texas, September. (idea processors, implementation, evaluation) GROVE is a prototype outline editor specifically designed for use by a group of people working simultaneously on the same text outline. It has been used in work sessions by several groups, both in face-to-face and distributed modes, for a variety of design tasks. This paper describes the function of GROVE and presents some of the important observations from these work sessions.

Ellis, C., Gibbs, S. J. and Rein, G. (1988b) "The Groupware project: An overview.” Technical report STP-033-88, MCC, Austin, Texas, January.

(face-to-face meetings, implementation, experiment, critique) This paper is an overview of the Groupware Project at MCC. The goals and design philosophy of three prototype systems are presented, including: highlights of past work on Project Nick; a summary of key findings from an extensive empirical study of Project Nick; and brief descriptions of HyperMate, Liza, and Grove.

Ellis, C. and Nutt, G. (1980) "Office information systems and computer science." ACM Computing Surveys, 12(1), p27-60. Reprinted in Greif, 1988. (overview) This paper gives a general (although now dated) survey of computer science research in office information technology.

Engelbart, D. (1963) "A conceptual framework for the augmentation of man's intellect." In Vistas in Information Handling, 1, p1-29, P. Howerton ed., Washington, DC, Spartan Books. Reprinted in Greif, 1988.

(conceptual, organizational concerns, social impact) Engelbart discusses his framework for understanding how human capabilities can be augmented through use of artifacts, language and training. Through a systems-engineering approach, he says that people and the computer system must be "designed together," so that people can incrementally master new skills.

Engelbart, D. (1982) “Towards high-performance knowledge workers." In OAC'82 Digest: Proceedings of the 1982 AFIPS Office Automation Conference, p279-290, San Francisco, California, April 5-7. Reprinted in Greif, 1988.

(implementation, shared views, data-sharing, face-toface meetings) This paper is an updated restatement of Engelbart's 1963 framework paper. He also includes an architectural overview of the NLS/Augment implementation.

Engelbart, D. (1984) “Authorship provisions in Augment." In Proceedings of the IEEE Computer Society International Conference--CompCon. Reprinted in Greif, 1988. (implementation, shared workspace, data-sharing, face-to-face meetings) This is one of the several papers that discuss the implementation of the nowvisionary Augment/NLS system. 
Engelbart, D. and English, W. (1968) “A research center for augmenting human intellect." In Proceedings of the Fall Joint Computing Conference, 33(, p395-410, Montvale, NY, AFIPS Press. Reprinted in Greif, 1988. (implementation, shared views, data-sharing, face-toface meetings) This is one of the several papers that discuss the visionary Augment/NLS system.

Engelbart, D. and Lehtman, H. (1988) "Working together." Byte, December.

(implementation, shared workspace, data-sharing, face-to-face meetings) This paper gives a popular review of the NLS/Augment system, discussing it in terms of document development, production and control; research intelligence; community handbook development; computer-based instruction and shared screens; meeting and conferences; community management; and special knowledge work by individuals and teams.

Engelbart, D. C. (1990) "Knowledge-domain interoperability and an open hyperdocument system." In Proceedings of the Conference on Computer Supported Cooperative Work (CSCW '90), Los Angeles, California, October 7-10, ACM Press.

(organizational concerns, hypertext) This paper is concerned with the "interoperability between knowledge domains", ie that knowledge in different fields (and in different forms) should be integrated within one coherent source. An "open hyperdocument system" is suggested as the backbone for interoperability. Issues concerned with this type of hypertext system are raised, and its essential elements provided.

Engestrom, Y., Engestrom, R. and Saarelma, O. (1988) "Computerized medical records, production pressure and compartmentalization in the work activity of health center physicians." In Proceedings of the Conference on ComputerSupported Cooperative Work (CSCW'88), p6584, Portland, Oregon, September 26-28, ACM Press.

(participatory design, social impact) This paper examines some aspects of communication between physicians in a group practice, focusing on the medical record as a communicative artifact. The role of computerized medical records are discussed in this light.

Ensor, J. R. (1989) "Rapport: A multimedia conferencing system." The ACM SIGGRAPH Video Review Supplement to Computer Graphics, 45(5). ACM Press, Baltimore, MD. Videotape. (remote meetings, shared views) This videotape illustrates the Rapport multimedia conferencing system.

Ensor, J. R., Ahuja, S. R., Horn, D. N. and Lucco, S. E. (1988) "The Rapport multimedia conferencing system--a software overview." In Proceedings of the 2nd IEEE Conference of Computer Workstations, p52-58, Santa Clara, March 7-10. (remote meetings, shared views) Rapport is a multimedia conferencing system that supports interactive, real-time, distributed conferences among two or more people. Rapport provides basic mechanisms to create, manage, and terminate conferences (data and voice is supported over the network). Existing programs can be shared. The paper discusses Rapport software: the user interface, the conference server, and its system levels.

Erickson, T. (1989) "An eclectic look at CSCW '88." ACM SIGCHI Bulletin, 20(5), p56-64, July. (report) This report provides another review of ACM's 1988 CSCW conference, held in Portland, Oregon. In particular, Erickson looks at problems with existing systems in general and the Coordinator in particular, real world case studies, and laboratory prototypes.

Eveland, J. D. and Bikson, T. (1987) "Evolving electronic communication networks: An empirical assessment." Office: Technology and People, 3. An earlier version was published in CSCW '86. (email, evaluation, organizational impact) The paper presents the results of an analysis of the communication patterns that characterize The Rand Corporation's use of RandMail, its electronic messaging system. The goal of the work was to explore and assess the development of electronic messaging systems in the context of expanding use. A variety of quantitative properties of these communication networks are presented, including both sociometric structures and network metrics.

Eveland, J. D. and Bikson, T. K. (1988) "Work group structures and computer support: A field experment." In Proceedings of the Conference on Computer-Supported Cooperative Work (CSCW '88), p324-343, Portland, Oregon, September 2628, ACM Press.

(evaluation, email) This excellent study considered two slightly different groups in a natural office setting. Both groups comprised two types of people: normal employees who worked in the office, and exemployees (retirees) who were usually at home.The overall interpretation is that email significantly and directly affects the outcomes and the process of cooperative work.

Fafchamps, D., Reynolds, D. and Kuchinsky, A. (1989) "The dynamics of small group decision making over the e-mail channel." In Proceedings of the 1st European Conference on Computer Supported Cooperative Work (EC-CSCW'89), Gatwick, UK, September 13-15, Computer Sciences House, Sloug, UK. (asynchronous conferencing, evaluation) A coding scheme was used to explore the dynamics of email discussions in a design team who used it for decision making support. Findings suggest that discussions display similar group task activities but few groupcentered strategies seen in face to face meetings; and that verbal devices may serve a different function when used in email discussions. The role of the discussion leader is raised. 
Fanning, T. and Raphael, B. (1986) "Computer teleconferencing: Experience at Hewlett Packard." In Proceedings of the Conference on ComputerSupported Cooperative Work (CSCW '86), p291306, Austin, Texas, December 3-5, ACM Press. (asynchronous conferencing, evaluation, organizational concerns) This paper describes Hewlett-Packard's experience with the large-scale introduction and use of Confer, an asynchronous conferencing system. Discussed is its role in the corporate communications environment; some examples of prominent successes and failures; some heuristics for how to make the best of the technology; and some suggestions for future capabilities that would make such systems more widely useful.

Farallon (1988) “Timbuktu user's guide." Farallon Computing Inc., Berkely, California. User's manual.

(shared views) This manual describes Timbuktu, a system that allows geographically dispersed users to share views and serial interactions with their Macintosh-based application programs.

Feldman, M. (1987) "Constraints on communication and electronic messaging." Office: Technology and People, 3. An earlier version was published in CSCW '86.

(email, organizational concerns, evaluation) The author suggests that some new communication occurs in large organizations that have electronic mail, because it allows people to find other people wth common interests at low cost to either party. This new communication creates links between people who would otherwise not share informaton.

Granovetter's work on "weak ties" is discussed in this context.

Ferwanger, T., Wang, Y., Lewe, H. and Krcmar, H. (1989) "Experiences in designing the Hohenheim CATeam Room." In Proceedings of the 1st European Conference on Computer Supported Cooperative Work (EC-CSCW '89), Gatwick, U.K., September 13-15, Computer Sciences House, Sloug, UK.

Finholt, T., Sproull, L. and Kiesler, S. (1990) "Communication and performance in ad hoc task groups." In Intellectual Teamwork: Social Foundations of Cooperative Work, p291-326, J. Galegher, R. E. Kraut and C. Egido ed., Hillsdale, New Jersey, Lawrence Erlbaum Associates. (email, evaluation, organizational concerns.) The use of electronic mail in student work groups is evaluated, where groups had similar tasks but used email to different degrees. Groups that frequently used email out-performed those that did not, especially by making coordination easier. Further, email changes the pattern of work, not just the output of work. The paper speculates on the larger organizational implications.

Fish, R. S. (1989) "Cruiser: A multi-media system for social browsing." The ACM SIGGRAPH
Video Review Supplement to Computer Graphics, 45(6). ACM Press, Baltimore, MD. Videotape. (informal meetings, virtual hallways) This videotape describes the motivations behind, and the key features of the Cruiser interface, a system for creating audio and video links through a virtual hallway.

Fish, R. S., Kraut, R. E. and Chalfonte, B. L. (1990) "The VideoWindow system in informal communications." In Proceedings of the Conference on Computer Supported Cooperative Work (CSCW '90), p1-11, Los Angeles, California, October 7-10, ACM Press. (video, informal meetings, virtual hallways, evaluation) VideoWindow is a very large screen, full duplex teleconferencing system used to support informal communication. The VideoWindow links two common rooms, allowing people in each area to communicate through it. The authors evaluate and discuss implications about the system in terms of transparency (how different it is from face to face), reciprocity (that people across the space can both see and hear each other), privacy, environmental context, social context, conversational regulation, and social relationships.

Foster, G. and Stefik, M. (1986) "Cognoter: Theory and practice of a Colab-orative tool." In Proceedings of the Conference on ComputerSupported Cooperative Work (CSCW '86), p7-15, Austin, Texas, December 3-5, ACM Press. (idea processor, face to face meetings) Cognoter is a program used in the Xerox CoLab that helps a cooperating group of people organize their thoughts for a presentation. It provides a multi-user interface and a structured meeting process. An annotated graph of ideas is built up by the group in three stages: brainstorming, ordering, evaluation.

Gabarro, J. J. (1990) "The development of working relationships." In Intellectual Teamwork: Social Foundations of Cooperative Work, p79-110, J. Galegher, R. E. Kraut and C. Egido ed., Hillsdale, New Jersey, Lawrence Erlbaum Associates. (social impact) The paper describes both the affective and instrumental components of relationships with co-workers, focusing on the stages through which work relationships move and the establishment of trust among members of a work team. Elements underlying personal relationships that also apply to work relationships are also identified.

Gale, S. (1989) "Adding audio and video to an office environment." In Proceedings of the 1st European Conference on Computer Supported Cooperative Work (EC-CSCW '89), Gatwick, U.K., September 13-15, Computer Sciences House, Sloug, UK.

Galegher, J., Kraut, R. and Egido, C. (ed.) (1990a) "Intellectual teamwork: Social and technological foundations of cooperative work." , Hillsdale, NJ, Lawrence Erlbaum Associates. (gale-krau:90) This important book of nineteen collected readings emphasises intellectual teamwork. It covers the social and behavioural processes about groups and organizations, as well as the 
technological expertise required to build supporting systems. Chapter headings are: 1 Basic social processes; 2 Field studies of collaborative work; 3 Experiences with technology for cooperative work; and 4 Technology for cooperative work.

Galegher, J. and Kraut, R. E. (1990b) "Computermediated communication for intellectual teamwork: A field experiment in group writing." In Proceedings of the Conference on Computer Supported Cooperative Work (CSCW'90), Los Angeles, California, October 7-10, ACM Press. (asynchronous conferencing, social impact, evaluation) This paper is concerned with intellectual teamwork, where people work together over substantial periods of time to create informationintensive products. The variations of the members needs over time suggest that different communication modalities may be useful at successive sages in the life of a long-term project. Computer-mediated communication (CMC) is often used for some of these stages. To access the utility of CMC for the various types and phases of intellectual teamwork, an experimented was conducted in which participants carried out complex collaborative writing project. Assessed were the effect of task divisibility and communication modality on work processes, group performance, and individual experiences, as well as the extent to which group members felt that the group was a viable and cohesive social identity.

Galegher, J. and Kraut, R. E. (1990c) "Technology for intellectual teamwork: Perspectives on research and design.” In Intellectual Teamwork: Social Foundations of Cooperative Work, p1-20, J. Galegher, R. E. Kraut and C. Egido ed., Hillsdale, New Jersey, Lawrence Erlbaum Associates. (overview, report) This paper introduces Galegher, Kraut and Egido's 1990 book on Intellectual Teamwork. Social science knowledge about groups and organizations could be extremely valuable in designing tools to help people communicate and structure their work, yet this knowledge is under-used, for reasons presented in the paper. The authors recommend that social scientists should become actively and directly involved in design.

Garcia-Luna-Aceves, J. J., Craighill, E. J. and Lang, R. (1988) “An open-systems model for computersupported collaboration." In Proceedings of the 2nd IEEE Conference of Computer Workstations, p40-51, Santa Clara, March 7-10.

(shared view, decision support) In this paper, the authors explore the functions and structure of systems for CSCW; describe MOSAIC, a model for CSCW systems that provides, amongst other things, a shared view; and discuss a prototype designed to support collaborative decision making.

Garfinkel, D., Gust, P., Lemon, M. and Lowder, S. (1989) "The SharedX multi-user interface user's guide, version 2.0.” Research report STL-TM-8907, Hewlett-Packard Laboratories, Palo Alto, California, March.

(shared views, implementation) SharedX is a multiuser environment that enables users to collaborate dynamically with others via their workstations. SharedX allows users to share existing $X$ based applications by replicating the window interface among users. The system is described and some issues reported.

Garrett, L. N., Smith, K. and Meyrowitz, N. (1986) "Intermedia: Issues, strategies and tactics in the design of a hypermedia document system." In Proceedings of the Conference on ComputerSupported Cooperative Work (CSCW'86), p163174, Austin, Texas, December 3-5, ACM Press. (hypertex, multimedia) Hypermedia provides a tool for cooperative work by allowing writers and designers to share a network of linked documents where they can create documents, link their own and others' documents together, and leave notes for one another. This paper discusses issues that designers need to address in the development of hypermedia, eg what kind of linking, contexts, and visual modeling the system provides. A variety of solutions are presented, including the ones implemented in Intermedia.

Gasparotti, P. and Simone, C. (1990) "A user defined environment for handling conversations." In Proceedings of IFIP WG8.4 Conference on MultiUser Interfaces and Applications, Crete, S. Gibbs and A. A. Verrighn-Stuart (ed), North Holland.

Gerrissen, J. F. and Daamen, J. (1990a) "Inclusion of a 'sharing' feature in telecommunication services." In 13th International Symposium HFT '90 Human Factors in Telecommunications, Torino, Italy, September 10-14.

(shared workspace, remote meetings, evaluation) This paper contrasts human performance and communicative behaviour when using a shared fused video workspace (where participants have a shared work and gestural space) versus a traditional videophone setting (where participants can only see the others work space and gestures, but cannot share it). The workspace stimulated patterns of communicative expressions and employment of multimodal information exchange which are present in face-to-face situations but absent in traditional telecommunication use.

Gerrissen, J. F., Itegem, J. V. and Daamen, J. (1990b) "Simple-Simon's GesturePad: A puppet for added expressiveness in communication and interaction." In SIGCHI'90: Conference on Human Factors in Computing Systems, Seattle, Washington, April 1-5. Poster presentation. (shared workspace, remote meetings) The authors describe how a limited number of on-screen hand postures (gestures) can be invoked from a keypad. The gestures not only add a new interaction technique to the interface, but are also useful for supporting computer-mediated communication between people, for example remote sharing of a workspace.

Gibbs, S. and Verrijn-Stuart (ed.) (1990) "Proceedings of IFIP WG8.4 Conference on Multi-User Interfaces and Applications (Crete)." , Amsterdam, North Holland. 
(collection) Session titles included: 1 Multi-user interface design; 2 Cooperative development of software; 3 Shared environments; 4 Desktop conferencing and multi-user editing; 5 Messaging; 6 Experiences with multi-user applications; and 7 Coordination.

Gibbs, S. J. (1989) "LIZA: An extensible groupware toolkit." In Proceedings of the SIGCHI Human Factors in Computing Systems, p29-35, Austin, Texas, April 30-May 4, ACM Press. (remote meetings, shared workspace) This paper presents a model of group tools based on active objects. The model has been applied to the design and implementation of an extensible groupware toolkit known as LIZA. The architecture and group tools available in LIZA are described, and multi-user design problems noted.

Goodman, G. and Abel, M. (1987a) "Collaboration research in SCL." Office: Technology and People, 3. An earlier version was published in CSCW '86. (remote meetings, evaluation) This paper reports on the second year of Xerox PARC's investigation of the support and enhancement of collaboration, with emphasis on the two-sit distributed organization of the System Concepts Laboratory (the Portland Experiment).

Goodman, G. and Abel, M. (1987b) "Communication and collaboration: Facilitating cooperative work through communciation." Office: Technology and People, 3(2), p129-146.

(informal meetings, video, virtual hallways) This report describes the Xerox video wall between Portland and Palo Alto.

Gorry, G. A., Burger, A. M., Chaney, R. J., Long, K. B. and Tausk, C. M. (1988) "Computer Support for Biomedical Work Groups.” In Proceedings of the Conference on ComputerSupported Cooperative Work (CSCW'88), p3951, Portland, Oregon, September 26-28, ACM Press.

(semi-structured messages, hypertext) The paper examined how members of a biomedical research group could coordinate efforts and share information. The authors' aim is to allow a researcher to scan, filter and manage information, to use the information for decision-making, and to disseminate it to the rest of the team and to outsiders through a "web" of interactions. In their implementation, users can structure or filter their information and their collaborations through sets of templates (structured messages), each tailored to fit a task. Templates exist, for example, for searching on-line medical databases and for sending and selectively receiving mail. Through templates, a uniform interface is created between group members and sources of information. Furthermore, all information can be pasted and presented in a hypertext system which allows its users to share information to the degree appropriate to their activities.

Gould, J. D. and Boies, S. J. (1983) "Human factors challenges in creating a principal support office system - The speech filing system approach."
ACM Trans Office Information Systems, 1(4), p273-298. Also published in Baecker \& Buxton, 1987.

(email, multimedia) This paper describes the key behavioural challenges in designing the speech filing system, a voice store and forward message system with which users compose, edit, send, and receive audio messages using telephones as terminals.

Gould, J. D. and Boies, S. J. (1984) "Speech filing - An office system for principles." IBM Systems Journal, 23(1), p65-81. Also published in Baecker \& Buxton, 1987.

(email, multimedia, social impact) This paper describes the purpose behind the speech filing system and its user interface.

Gray, P. (1987) "Group Decision Support Systems." Decision Support Systems (North-Holland)(3), p233-242.

(decision support, face-to-face meetings, overview) The paper focuses on one type of group decision support system, a decision room in which computers and communications are used by participants during their deliberations. The paper introduces the concepts of private work, public screen, and chauffeur. It also reports on the experimental evidence of use, with special attention given to the potential of using gaming.

Greenbaum, J. (1988) "In search of cooperation: An historical analysis of work organization and management strategies." In Proceedings of the Conference on Computer-Supported Cooperative Work (CSCW '88), p102-114, Portland, Oregon, September 26-28, ACM Press.

(participatory design, social impact) Greenbaum offers a historical perspective of work organization and management strategies. In essence, she argues that the Scandinavian view of user participation in the design process is part of building democracy in the workplace. She indicates two central issues in the move to workplace democracy. First, democracy needs to be viewed as active participation in planning and decision-making, thus making worker involvement far more than techniques for improved human-computer interfaces. Second, CSCW means that computer systems need to reinforce forms of cooperation that enhance the chance for a more democratic workplace. For example, information flow in a CSCW application could emphasize lateral movement, as opposed to the top-down flow through authority normally seen in management. Planning functions could then move from current rule-based bureaucratic realms to situations where groups assume the stronger role.

Greenberg, S. (1989) “The 1988 Conference on Computer-Supported Cooperative Work: Trip Report." ACM SIGCHI Bulletin, 20(5), p49-55, July. Also published in Canadian Artificial Intelligence, Volume 19, April. (report) This report provides a comprehensive review of ACM's 1988 CSCW conference, held in Portland, Oregon. 
Greenberg, S. (1990a) "Feasibility study of a national high speed communications networks for research and development: Future applications." Research Report, Learning and Collaborationg Group , Advanced Computing and Engineering Department, Alberta Research Council, Calgary, Alberta.

(overview) This report is part of a large study investigating the feasibility of a national high speed communications network supporting researchers and developers. It emphasises the future applications made of this network, with much discussion of the many different kinds of CSCW-styles of applications. Some of its sections are: computer support for real-time remote conferencing; casual real-time interaction; asynchronous messaging; bulletin boards and asynchronous conferencing; access and operation of distributed resources; digital libraries; and application areas.

Greenberg, S. (1990b) "Personalizable groupware: Accomodating individual roles and group differences." Presented at CSCW'90 Workshop on Groupware Implementation in Computing Systems and Social Systems, Los Angeles, October 7. Also available as Research Report 90/404/28, Dept of Computer Science, University of Calgary, Alberta, Canada. A revised version was submitted to EC-CSCW '91. (conceptual, shared views) For groupware to be considered successful, it must be usable and acceptable by every member of the group. Yet the differences present between group members-their varying roles, needs, skills-and the differences between groups are a serious obstacle to achieving uniform acceptance of the groupware product, especially when the product treats all people and groups identically. This paper discusses the consequences that may occur as a result of not accommodating individual differences, and then offers a possible solution to the problem. First, instances of groupware failure are described: the inability of the group to reach a critical mass; the unequal accessibility of the groupware by participants; the failure to accommodate the different roles participants may play; the failure to balance the work done against the benefits received; and the failure of groupware to evolve with the needs of the group. Second, the notion of personalizable groupware is proposed, defined as a system whose behaviour can be altered to match the particular needs of group participants and of each group as a whole. Finally, the paper presents a working example of personalized groupware. Share is a shared screen system that offers its users a flexible choice of floor control models to help them mediate their interactions with the shared application.

Greenberg, S. (1990c) "Sharing views and interactions with single-user applications." In Proceedings of the ACM/IEEE Conference on Office Information Systems, p227-237, Cambridge, Massachusets, April 25-27. (shared views, overview, implementation) This report discusses several roles and responsibilities of view-sharing software that must be considered during its design and evaluation: view management, floor control, conference registration by participants, and handling of meta-level communications. A brief survey of existing shared view systems is provided, and several innovative new directions are described.

Greenberg, S. (1991a) "An annotated bibliography of computer supported cooperative work." SIGCHI Bulletin, July. Continually updated versions are available as Research Report, Dept of Computer Science, University of Calgary, Calgary, Alberta. (overview, report) This report provides a bibliography of computer supported cooperative work. Most of the over 300 entries are annotated with a brief description derived from snippets from the original abstract, personal notes, and from commentaries written by other people. Annotations also include a keyword list for topic disambiguation. The report also includes and overview of the general sources that publish CSCW works. A list of groupware systems and concepts are listed and indexed to the bibliography.

Greenberg, S. (1991b) "Computer supported cooperative work and groupware: An introduction to the special edition." Int J Man Machine Studies, 34(2), p133-143, February. In the special edition on CSCW \& Groupware. Republished in Greenberg, 1991.

(collection, overview) This article introduces a special edition on CSCW and groupware (published across two journal numbers). CSCW and groupware are introduced and an overview of the sixteen articles is provided. A "further readings and sources" section is included. See Greenberg 1991c.

Greenberg, S. (ed.) (1991c) "Computer supported cooperative work and groupware." A book in the Computer and People Series, London, Academic Press.

(collection) This edited book contains the following articles, most which were originally published in the February/March issues of the International Journal of Man Machine Studies special edition on CSCW and groupware.

1 Computer Supported Cooperative Work and Groupware, Greenberg;

2 Finding from observational studies of collaborative work, Tang;

3 Twinkling lights and nested loops: Distributed problem solving and spreadsheet development, Nardi;

4 Design for conversation: Lessons from Cognoter, Tatar;

5 The Portland Experience: A report on a distributed research group, Olson;

6 Power, ease of use, and cooperative work in a practical multimedia message system, Borenstein;

7 Electronic meeting support: the GroupSystem concept, Valacich;

8 Computer-mediated communication, deindividuation, and group decision-making, Lea;

9 Conversational flexibility in a computer 
conference used in professional education,

Weedman;

10 Multidimensional audio window management, Cohen;

11 Liveware: A new approach to sharing data in social networks, Witten;

12 rIBIS: A real-time group hypertext system, Rein;

13 Modelling groupware in the electronic office, Cook;

14 Post-mechanistic groupware primitives: Rhythms, boundaries and containers, JohnsonLenz;

15 Structure and support in cooperative environments: The Amsterdam Conversation Environment, Dykstra;

16 Obstacles to user involvement in software product development, with implications for CSCW, Grudin;

17 Cooperative prototyping--Users and designers in mutual activity, Bodker;

18 An annotated bibliography of Computer

Supported Cooperative Work, Greenberg.

Greenberg, S. and Bohnet, R. (1991) "GroupSketch:

A multi-user sketchpad for geographicallydistributed small groups." In Proceedings of Graphics Interface '91, Calgary, Alberta, July. Reseach report 90/414/38, Dept of Computer Science, University of Calgary, Alberta, Canada. (shared workspace, implementation, evaluation) A workstation-based tool called GroupSketch has been developed that allows a small geographicallydistributed group to list, draw, and gesture simultaneously in a communal work surface, supporting interactions similar to those occurring in the face-to-face process. The design principles behind GroupSketch is discussed as well as the architecture of its implementation. Observations of use indicated that people use GroupSketch in much the same way they use face to face communal sketchpads.

Greenberg, S. and Chang, E. (1989) “Computer support for real time collaborative work." In Proceedings of the Conference on Numerical Mathematics and Computing, Winnipeg, Manitoba, September 28-30. Available in Congressus Numerantium vol 74 and 75 . (overview, face to face meetings) A large portion of an office worker's time involves real time collaboration with fellow associates. Many traditional tools assist this process, such as telephones, meeting rooms, specialized media such as whiteboards, and so on. This paper is concerned with the potential of the computer as a tool to further enhance the group work process through direct support of real time communication needs and the specific collaboration requirements of the group. General computer support for four styles of real-time interactions are distinguished and surveyed: 1) face to face meetings; 2) remote conferencing; 3) casual real time interaction; and 4) multi-user applications. Each topic is introduced, motivations discussed, and the key technical systems and related research described.
Greif, I. (1988) Computer-supported cooperative work: A book of readings, Morgan Kaufmann Publishers Inc, San Mateo, California.

(collection) This book is perhaps the best collection of previously-published (and sometimes hard to get) papers on computer-supported cooperative work. The book is divided into three major parts: visions and first steps; new technologies for CSCW; and CSCW design theories.

Greif, I. and Sarin, S. (1987) "Data sharing in group work." ACM Trans Office Information Systems, 5(2), p187-211, April. Reprinted in Greif, 1988. An earlier version appeared in CSCW '86. (data sharing) This paper discusses issues in data sharing in group work from a data management requirements. Support technologies range from conventional data base management systems for regular information to object management systems for irregular information storage and retrieval. This paper examines the data management requirements of group work applications on the basis of experience with three prototype systems--two calendar systems and one collaborative document editing system. Unresolved issues of access control and concurrency are raised.

Grudin, J. (1988a) "Perils and pitfalls." Byte, December.

(critique, organizational concerns) Grudin describes the perils and pitfalls of groupware design. In particular he describes why applications can fail. This paper is a popular version of the excellent one presented in the 1988 CSCW conference and his 1988 MCC technical report.

Grudin, J. (1988b) "Why CSCW applications fail: Problems in the design and evaluation of organizational interfaces." In Proceedings of the Conference on Computer-Supported Cooperative Work (CSCW '88) (CSCW '88), p85-93, Portland, Oregon, September 26-28, ACM Press. (critique, organizational concerns) Grudin discusses why CSCW applications fail. First, there is a disparity between those who will benefit from a CSCW application and those who must do additional work to support it. Second, there is a decisionmaking failure that leads to ill-fated development efforts, due to the lack of management intuition for these applications. Third, there is a failure to learn from actual experience because it is extremely difficult to evaluate these applications. Grudin suggests that we must be aware of these problems if we are to overcome them.

Grudin, J. (1989a) "CSCW '88: Report on the conference and review of the proceedings." $A C M$ SIGCHI Bulletin, 20(4), p80-84. (report) A review of ACM's 1988 CSCW conference, held in Portland, Oregon.

Grudin, J. (1989b) "Why groupware applications fail: Problems in design and evaluation." Office: Technology and People, 4(3), p245-264. (critique, organizational concerns) Grudin describes three reasons why groupware applications can fail. This paper is an expanded version of the excellent 
one presented in the $1988 \mathrm{CSCW}$ conference. See also his December 1988 Byte article.

Grudin, J. (1990a) "Groupware and cooperative work: Problems and prospects." In The art of humancomputer interface design, p171-185, B. Laurel ed., Reading, Massachusetts, Addison-Wesley. (overview, critique) The first half of the chapter describes problems that have led to expensive, repeated failures of groupware development efforts. In the second half, a groupware success story demonstrates the importance of focusing our analysis on the work setting and provides a basis for speculating about the future.

Grudin, J. (1990b) "interface." In Proceedings of the Conference on Computer Supported Cooperative Work (CSCW'90), Los Angeles, California, October 7-10, ACM Press.

(critique) This is an essay on "the user interface" to a computer and "the computer interface" to a user or users. It also addresses a "user's or group's interface" to a computer and a "computer's interface" to a user or users. After noting the further distinction of users' interfaces to their work, it concludes with a discussion of "the designer" and designers' "models of users." A delightful essay on what is really meant or implied by interface terminology.

Grudin, J. (1991a) "CSCW: The convergence of two disciplines." In ACM SIGCHI Conference on Human Factors in Computing Systems, New Orleans, April 28-May 2, ACM Press. (conceptual, social impact) This essay provides an excellent discussion/review of the CSCW field, its early roots and derivations, what it is and isn't, and how it is perceived by today's community. In particular, CSCW is discussed as the convergence of two development disciplines, one concerned with small-groups, and the other with large systems. It provides a much-needed perspective on the CSCW "paradigm".

Grudin, J. (1991) "Obstacles to user involvement in software product development, with implications to CSCW." Int J Man Machine Studies, 34(3), p435-452, March. In the special edition on CSCW \& Groupware. Republished in Greenberg, 1991. (participatory design, organizational concerns, software design) While participatory design has generally succeeded for software development targetted to producing systems specific to an inhouse organizational context, it has not really been applied to product development organizations that design mass-produced off-the-shelf products. Grudin suggests that in spite of the benefits participatory design may offer for improving a system interface (particularly for groupware systems), there are several serious obstacles to user involvement. Most stem from organizational structures and development practices that arose prior to the current market for interactive systems.

Grudin, J. (1991c) "A tale of two cities: Reflections on CSCW in Europe and the United States." SIGCHI Bulletin, July. (report) This essay contrasts ideas about CSCW in Europe and in America by focusing on the different viewpoints in the EC-CSCW and the ACM CSCW conference.

Gust, P. (1988) "SX: An experiment with using shared windows to support cooperative work." Hewlett-Packard Laboratories, California, February. Unpublished draft. (shared views, implementation) This is an early draft paper on the SharedX window system.

Gust, P. (1989) "Multi-user interfaces for extended group collaboration." In Proceedings of the Groupware Technology Workshop, Xerox PARC, Palo Alto, California, August.

(shared views) Gust describes SharedX in the context of a venue-agile system.

Gutek, B. A. (1990) "Work group structure and information technology: A structural contingency approach.” In Intellectual Teamwork: Social Foundations of Cooperative Work, p63-78, J. Galegher, R. E. Kraut and C. Egido ed., Hillsdale, New Jersey, Lawrence Erlbaum Associates. (organizational concerns, social impact) Structural contingency theory, which suggests that an effective organization or work group must fit its technology to the structure of its tasks, can be used to guide research on computer use in cooperative work. The theory is explained and used as a framework for analyzing the influence of information technology on work group effectiveness.

Guttman, S. (1989) "Farallon: Building the ultimate network." MicroTimes, 6(7), July. (implementation) Steve Guttman interviews Reese Jones of Farallon Inc. Jones discusses cheap networking on PC's, the screen/sound recorder, multimedia, and groupware via shared views in the Timbuktu program.

Hahn, U., Jarke, M., Kreplin, K. and Farusi, M. (1989) "CoAUTHOR: A hypermedia group authoring environment." In Proceedings of the 1st European Conference on Computer Supported Cooperative Work (EC-CSCW'89), Gatwick, U.K., September 13-15, Computer Sciences House, Sloug, UK.

Hahn, U., Jarke, M. and Rose, T. (1990) "Group work in software projects." In Proceedings of IFIP WG8.4 Conference on Multi-User Interfaces and Applications, Crete, S. Gibbs and A. A. VerrighnStuart (ed), North Holland.

Halasz, F. G. (1988) "Reflections on Notecards: Seven issues for the next generation of hypermedia systems." Comm ACM, 31(7), p836-852, July. (hypertext, multimedia) This article presents NoteCards as a foil against which to explore some of the major limitations of the current generation of hypermedia systems, and characterizes the issues that must be addressed in designing the next generation systems.

Halonen, D., Horton, M., Kass, R. and Scott, P. (1989) "Shared hardware: A novel technology for computer support of face to face meetings." In 
Proceedings of the Groupware Technology Workshop, Xerox PARC, Palo Alto, California, August 24-25. Also available as Report CMI-89015, Center for Machine Intelligence, Ann Arbor, MI.

(face-to-face meetings, shared views) The Capture Lab supports a shared hardware approach to groupware where meeting participants with their own private machines can access and transfer material to a public computer whose screen is being displayed at the front of a room. Advantages and limitation of this simple approach are briefly described.

Harper, R. R., Hughes, J. A. and Shapiro, D. Z. (1989) "Working in harmony: An examination of computer technology in air traffic control." In Proceedings of the 1st European Conference on Computer Supported Cooperative Work (ECCSCW '89), Gatwick, U.K., September 13-15, Computer Sciences House, Sloug, UK.

Harrison, S. (1989) "The office design project." The ACM SIGGRAPH Video Review Supplement to Computer Graphics, 45(4). Videotape.

(informal meetings) This videotape illustrates a team of three architects collaborating together over a video/audio/computing link.

Harrison, W., Ossher, H. and Sweeney, P. (1990)

"Coordinating concurrent development." In Proceedings of the Conference on Computer Supported Cooperative Work (CSCW'90), Los Angeles, California, October 7-10, ACM Press. Development of any large system or artifact requires coordination of many developers who often work concurrently. The goal of coordination is to enhance, not restrict, developer productivity while ensuring that concurrent development activities do not clash with each other. The paper presents a formal model of concurrent development, where development consists of a collection of modification activities that change files, and merges that combine the changes. The notion of coordination consistency ensures that changes are not inadvertently destroyed and that changes are correctly propagated to subsequent modification activities.

Hart, P. and Estrin, D. (1990) "Computer integration: A co-requirement for effective inter-organization computer network implementation." In Proceedings of the Conference on Computer Supported Cooperative Work (CSCW '90), Los Angeles, California, October 7-10, ACM Press. (organizational concerns) Inter-organization networks (IONs) provide significant opportunities for improving coordination between firms engaged in mutually dependent activities. The paper focuses on how IONs affect information processing requirements, and production and transaction costs when they interconnect firms with internally integrated computer systems and when they are used only as substitutes for conventional media.

Haslett, B. (1987) "Structural pragmatics: Managing conversations." In Communication: Strategic
Action in Context, p47-72, Hillsdale, New Jersey, Lawrence Erlbaum Associates.

(social impact) This chapter focuses on casual conversation. In particular, it discusses how we manage conversations successfully, with emphasis placed on turntaking.

Heath, C. (1991) "Disembodied conduct: Communicatio through video in a multi-media envrionment." In ACM SIGCHI Conference on Human Factors in Computing Systems, New Orleans, April 28-May 2, ACM Press.

Hellman, R. (1990) "User support: Illustrating computer use in collaborative work contexts." In Proceedings of the Conference on Computer Supported Cooperative Work (CSCW '90), Los Angeles, California, October 7-10, ACM Press. (organizational concerns, hypertext) It is relevant for users of a computerized information system to perceive the organizational context of collaborative work and corresponding information process. A theoretical framework for the realization of a context support system is presented, with four types of modules: images of information media; descriptions of jobs composed of task lattices; illustrations of physical work units; and visualizations of databases. Hypermedia is used as a potential implementation environment.

Hennessy, P. (1989) "Information domains in CSCW." In Proceedings of the 1st European Conference on Computer Supported Cooperative Work (EC-CSCW '89), Gatwick, U.K., September 13-15, Computer Sciences House, Sloug, UK.

Hiltz, S. R. (1988) "Collaborative learning in a virtual classroom: Highlights of findings." In Proceedings of the Conference on ComputerSupported Cooperative Work (CSCW '88), p282290, Portland, Oregon, September 26-28, ACM Press.

(education, evaluation) Hiltz describes a "virtual classroom." Goals included improving access and effectiveness of college-level courses through collaborative learning. On average, students report a better learning experience.

Holand, U. and Danielson, T. (1989) "The psychology of cooperation -- Consequences of descriptions, the power of creative dialogues." In Proceedings of the 1st European Conference on Computer Supported Cooperative Work (EC$C S C W$ '89), Gatwick, U.K., September 13-15, Computer Sciences House, Sloug, UK.

Hutchins, E. (1990) "The technology of team navigation.” In Intellectual Teamwork: Social Foundations of Cooperative Work, p191-220, J. Galegher, R. E. Kraut and C. Egido ed., Hillsdale, New Jersey, Lawrence Erlbaum Associates. (social impact, organizational concerns) This paper provides a specific instance of intellectual teamwork: team navigation on board of ships. For example, the physical layout of the control room provides opportunity for crew members to observe each other 
at work, contributing to partial redundancy in their knowledge of each others work and maintenance of the group over time.

Ishii, H. (1990a) "Cross-cultural communication and Computer Supported Cooperative Work.” In Whole Earth Review, p48-52, H. Rheingold ed., Sausalito, California, .

(social impact) This essay argues that groupware produces "cultural tools" that embody the protocol of a culture. Ishii argues that we should try to understand the nature of cross-cultural communication and to design systems to facilitate the cross-cultural communication process.

Ishii, H. (1990b) "Message-driven groupware design based on office procedure model: OM-1." Research report, NTT, Yokosuka-Shi, Kanagawa, Japan, June. Reprinted from the Journal of Information Processing, Information Processing Society, Japan. (organizational concerns) A design methodology for asynchronous groupware is proposed that can control and keep track of the progress of cooperative tasks among office workers who are geographically distributed. The methodology is based on COOKBOOK: cooperative work support based on organizational knowledge.

Ishii, H. (1990c) "TeamWorkStation: Towards a seamless shared space." In Proceedings of the Conference on Computer Supported Cooperative Work (CSCW'90), p13-26, Los Angeles, California, October 7-10, ACM Press. (shared workspace, video, remote meetings, implementation) TeamWorkStation is a real-time shared workspace. Its key ideas are the overlay of individual workspace video images and the creation of a shared drawing surface. Because each co-worker can continue to use his/her favorite application programs in the virtual shared workspace, the cognitive discontinuity between individual and shared spaces is greatly reduced. The technique of fusing workspaces is also described and compared with other approaches.

Ishii, H. and Arita, K. (1991) "ClearFace: Translucent multiuser interfce for TeamWorkstation.” Research report , NTT Human Interface Laboratories, Kanagawa, Japan, January. Submitted to ECCSCW '91.

(shared workspace, video, remote meetings, implementation) Because of the limitation of screen size, it is hard to secure space for a shared drawing window large enough for effective use on one screen together with all face windows of the group memebers. A new solution, called ClearFace, is proposed, where translucent face windows are overlayed onto shared workspace windows. ClearFace is implemented in the TeamWorkstation prototype.

Ishii, H. and Miyake, N. (1991-submitted) "TeamWorkStation: Towards an open shared workspace." Comm ACM. Also available from NTT Human Interface Labs, Kanagawa, Japan. (shared workspace, video, remote meetings, implementation) This paper integrates the CSCW '90 and IFIP WG8.4 Conference papers on TeamWorkstation.

Ishii, H. and Ohkubo, M. (1990a) "Design of TeamWorkStation: A realtime shared workspace fusing desktops and computer screen." In Proceedings of IFIP WG8.4 Conference on MultiUser Interfaces and Applications, Crete, S. Gibbs and A. A. Verrighn-Stuart (ed), North Holland. (shared workspace, implementation) Another in the series of articles describing TeamWorkstation.

Ishii, T., Kuzuoka, H., Takahara, T. and Myoi, T. (1990b) "Collaboration system for manufacturing system in the 21st century." In International Conference on Manufacturing Systems and Environment, Tokyo, Japan, May 28-June 2, Japan Society of Mechanical Engineers.

Submitted.

(video, remote meetings, implementation) Voice and video tools for informal communication between geographically distributed sites are described. Discussions include: superimposing a mouse cursor on a TV monitor and sharing a field of vision. A software toolkit to support groupware development is also offered.

Jackson, S. L. (1989) "Hypertext for computer conferencing." Research Report STL-89-8, Hewlett-Packard Laboratories, Palo Alto, Califiornia, June. From an MIT Master's thesis. (asynchronous conferencing, hypertext, evaluation) This thesis proposes that a hypertext interface be used to represent the messages in a computer conferencing system, with links connecting messages and replies. A prototype system called Banyan was designed and tested.

Jarrell, N. F. and Barrett, B. (1986) "Network-based systems for asynchronous group communication." In Proceedings of the Conference on ComputerSupported Cooperative Work (CSCW'86), p184191, Austin, Texas, December 3-5, ACM Press. (asynchronous conferencing, multimedia, implementation) This paper presents an architecture for a network-based system that models communication as group access to shared multimedia objects. It also describes the features of a computer conferencing system that was implemented for Bitnet.

Johansen, R. (1988) Groupware: Computer Support for Business Teams, The Free Press, Macmillan Inc., New York.

(overview, collection) A very readable layman's book detailing current approaches and applications of groupware to business teams. Still the best introduction to the groupware area now available.

Johansen, R. (1989) "Groupware: Future Direction and Wild Cards." In Proceedings of the Conference on Organizational Computing, Coordination, and Collaboration, Austin, Texas, November 13-14, 1989. 
(conceptual) This paper offers Johansen's personal speculations on where groupware is going over the next five years.

Johansen, R. and Bullen, C. (1984) "Thinking ahead: What to expect from teleconferencing." Harvard Business Review, p4-10, March/April. Reprinted in Greif, 1988.

(remote meetings, asynchronous conferencing, overview, critique, video) Several remote conferencing installations are reviewed and technologies discussed: audio, still video, text, fullmotion video, and live video. Some benefits of using these restricted modes over face-to-face meetings are provided. However, the impact of these technologies has not been as great as the authors expected.

Johnson, B. M., Weaver, G. M., Olson, M., Dunham, R. and McGonagill, G. (1986) "Using a computer based tool to support collaboration: A field experiment." In Proceedings of the Conference on Computer-Supported Cooperative Work (CSCW'86), p343-352, Austin, Texas, December 3-5, ACM Press. (email, evaluation, organizational concerns) This report describes a field experiment which focuses on the adaptation in work practices when groups of people are introduced to electronic communication tools (email) to support their collaborative work.

Johnson-Lenz, P. and Johnson-Lenz, T. (1991) "Postmechanistic groupware primitives: rhythms, boundaries and containers." Int J Man Machine Studies, 34(3), p385-418, March. In the special edition on CSCW \& Groupware. Republished in Greenberg, 1991.

(software design, social impact) Today's approach to groupware is mechanistic, ie based upon some social theory of human interaction or task-oriented approach that can be modelled by a machine. This article considers a "post-mechanistic" approach, where the model of group behaviour is not rigidly codified into the system but evolves with the group. An implementation considered post-mechanistic is described. It is particularly intriguing not only for technical reasons, but because the subject domain is "self-help", a far cry from the usual business-oriented applications emphasised by developers.

Joiner, R. and Blaye, A. (1989) "Mechanisms of cognitive change in peer interaction: Implications for the design of computer supported cooperative learning environments." In Proceedings of the 1st European Conference on Computer Supported Cooperative Work (EC-CSCW'89), Gatwick, U.K., September 13-15, Computer Sciences House, Sloug, UK.

Karbe, B. and Ramsperger, N. (1990) "Influence of exception handling on the support of cooperative office work." In Proceedings of IFIP WG8.4 Conference on Multi-User Interfaces and Applications, Crete, S. Gibbs and A. A. VerrighnStuart (ed), North Holland.

Kass, R., Barnhart, G., Dimercurio, M., Gotts, J. and Scott, P. (1989) "InVision: Augmenting communication in a large organization by modelling Its Members." In Proceedings of the Fourth Annual Rocky Mountain Conference on Artificial Intelligence. Also available as technical report CMI-89-004, Center for Machine Intelligence, Ann Arbor, Michigan.

InVision is a project that focuses on improving the coordination of work in a large organization by modelling the knowledge and information needs of its memebers. A "Yellow Pages" service is used to indicate which individuals in the organization are knowledgeable about particular parts. The model can be exploited by a mail routing system to help direct and filter messages that potentially affect individuals in a wide range of jobs.

Kedzierski, B. (1982) "Communication and management support in system development environments." In Proceedings of the ACM SIGCHI Conference on Human Factors in Computer Systems, p163-168, Gaithersburg, MD, March 15-17. Reprinted in Greif, 1988.

(protocols) Speech acts are specialized to recognize the communications between people when developing and maintaining a software system.

Keisler, S., Siegel, J. and McGuire, T. W. (1984)

"Social psychological aspects of computermediated communication." American Psychologist, 39, p1123-1134. Reprinted in Greif, 1988.

(evaluation, asynchronous conferencing) This paper looks at the application of social science methods to research the issues raised by computing and technological change. Their own study of a computermediated system is described.

Knister, M. J. and Prakash, A. (1990) "DistEdit: A distributed toolkit for supporting multiple group editors." In Proceedings of the Conference on Computer Supported Cooperative Work (CSCW '90), Los Angeles, California, October 7-10, ACM Press.

(software design, implementation) DistEdit is a toolkit for building applications that support collaboration between people in distributed environments. In particular, it allows one to build interactive group editors and has the ability to support different editors simultaneously. The toolkit allows existing single user editors to be modified slightly to become a multi-user system.

Koszarek, J. L., Lindstrom, T. L., Ensor, J. R. and Ahuja, S. R. (1990) “A multi-user document review tool." In Proceedings of IFIP WG8.4 Conference on Multi-User Interfaces and Applications, Crete, S. Gibbs and A. A. VerrighnStuart (ed), North Holland.

Kraemer, K. and King, J. (1988) "Computer-based systems for group decision support: Status of use and problems in development." Computing Surveys, 20(2), p115-146. An earlier version appeared in CSCW '86. (decision support, overview) Application of computer and information technology to cooperative 
work and group decisionmaking has grown out of three traditions: computer-based communications, computer-based information service provision, and computer-based decision support. This paper provides an overview of the various kinds of systems that have been configured to meet the needs of groups at work, evaluates the status of these systems in the USA, evalutates the experience with them, and assesses barriers to their further development and use.

Kraemer, K. L. and Pinsonneault, A. (1990)

"Technology and groups: Assessments of the empirical research." In Intellectual Teamwork: Social Foundations of Cooperative Work, p373404, J. Galegher, R. E. Kraut and C. Egido ed., Hillsdale, New Jersey, Lawrence Erlbaum Associates.

(decision support, overview, evaluation) The paper provides an up-to-date portrait of the state of our knowledge about group decision support systems (GDSS). Five major research implications are offered: the lack of research on some important "formal" factors of groups; the lack of knowledge of the impact of GDSS on the informal dimensions of a group; the need to move away from the lab towards real field studies; the relation between group development and how it affects GDSS; and how the structure imposed by technology affects group processes.

Krasner, H. (1987) “CSCW '86 conference summary report.” ACM/SIGCHI Bulletin, 19(1), p51-53. (report) A review of the CSCW '86 conference.

Krauss, R. M. and Fussell, S. R. (1990) "Mutual knowledge and communicative effectiveness." In Intellectual Teamwork: Social Foundations of Cooperative Work, p111-146, J. Galegher, R. E. Kraut and C. Egido ed., Hillsdale, New Jersey, Lawrence Erlbaum Associates.

(social impact, evaluation) Mutual knowledge occurs when people develop some idea of what their communicating partners know and don't know in order to formulate what they have to say to them. Speakers come to conclusions about their partners' states of knowledge through a number of mechanisms: by listening to what they themselves have said, by making inferences from their partner's category membership, or by relying on feedback. Experimental research illustrating mutual knowledge is described, and implications to communications technology is offered.

Kraut, R., Egido, C. and Galegher, J. (1988a) "Patterns of contact and communication in scientific collaboration." In Proceedings of the Conference on Computer-Supported Cooperative Work (CSCW '88), p1-12, Portland, Oregon, September 26-28, ACM Press.

(evaluation, informal meetings) This paper describes the influence of physical proximity on the development of collaborative relationships between scientific researchers and on the execution of their work. These descriptions provide the foundation for a discussion of the actual and potential role of communications technology in professional work, especially for collaborations carried out at a distance. Communication between people is shown to have an exponential decay with distance.

Kraut, R., Galegher, J. and Egido, C. (1988b) "Relationships and tasks in scientific research collaborations." Human Computer Interaction, 3(1), p31-58. Reprinted in Greif, 1988. An earlier version was published in CSCW '86.

(evaluation, informal meetings) This paper uses the results of studies of research collaborations among scientists to suggest design guidelines for computer technology aimed at supporting such collaboration. It shows that a great deal of emphasis will have to be placed on how researchers form and maintain their personal relationships.

Kraut, R. E., Egodo, C. and Galegher, J. (1990) "Patterns of contact and communication in scientific research collaborations." In Intellectual Teamwork: Social Foundations of Cooperative Work, p149-172, J. Galegher, R. E. Kraut and C. Egido ed., Hillsdale, New Jersey, Lawrence Erlbaum Associates.

(informal meetings, evaluation, social impact) The paper describes the influence of physical proximity on the development of collaborative relationships between scientific researchers and on the execution of their work. Key aspects supporting developing relationships include the importance of informal communication, the quality of communication, and the personal cost. Implications to technological support are offered.

Kreifelts, T., Victor, F., Woetzel, G. and Woitass, M. (1989) “A design tool for autonomous group agents." In Proceedings of the 1st European Conference on Computer Supported Cooperative Work (EC-CSCW '89), Gatwick, U.K., September 13-15, Computer Sciences House, Sloug, UK.

Kurbel, K. and Pietsch, W. (1990) “A cooperative work environment for evolutionary software development." In Proceedings of IFIP WG8.4 Conference on Multi-User Interfaces and Applications, Crete, S. Gibbs and A. A. VerrighnStuart (ed), North Holland.

Kyng, M. (1988) "Designing for a dollar a day." In Proceedings of the Conference on ComputerSupported Cooperative Work (CSCW'88), p178188, Portland, Oregon, September 26-28, ACM Press.

(participatory design, software design) Kyng offers a design methodology. He steps through the Scandinavian experiences with end user participation, and reviews several tools and techniques which will: 1) establish possibilities of alternative forms of work within the workplace; 2) evolve the local work situation through a cycle involving situation analysis, goal discussion, and investigation of possible courses of actions; 3 ) create a vision of new and different uses of technology; and 4) view the design through mock-up simulations. 
Lakin, F. (1988) “A performing medium for working group graphics." In Computer-supported cooperative work: A book of readings, I. Greif ed., San Mateo, California, Morgan Kaufmann Publishers Inc. An earlier version was published in CSCW '86.

(shared workspace) This paper analyzes the role in a meeting of shared text-graphic displays. He develops the notion of "text-graphic performance" that captures changes over time of the images. The results are important to the design of computerized shared workspaces.

Lakin, F. (1990) "Visual languages for cooperation: A performing medium approach to systems for cooperative work." In Intellectual Teamwork: Social Foundations of Cooperative Work, p453488, J. Galegher, R. E. Kraut and C. Egido ed., Hillsdale, New Jersey, Lawrence Erlbaum Associates.

(shared workspace, implementation) A visual language can give group members a way to visualize an aspect of group work so they can better understand and perform it. Lakin describes a computer graphics system called "vmacs" that has the potential to allow people to move seamlessly between individual and group modes of work, between graphic and text work objects, and between casual and formal representations of objects.

Landow, G. P. (1990) "Hypertext and collaborative work: The example of Intermedia." In Intellectual Teamwork: Social Foundations of Cooperative Work, p407-428, J. Galegher, R. E. Kraut and C. Egido ed., Hillsdale, New Jersey, Lawrence Erlbaum Associates.

(hypertext, multimedia, education) When used in an educational context, hypermedia encourages undergraduate students to move beyond passive learning to to active, generative scholarly work. The experiences of Intermedia use are described.

Lantz, K. (1986) "An experiment in integrating multimedia conferencing." In Proceedings of the Conference on Computer-Supported Cooperative Work (CSCW '86), Austin, Texas, December, ACM Press. Reprinted in Greif, 1988. (shared views) This paper describes Lantz's experience in designing a centralized shared view system.

Lantz, K. A., Lauwers, C., Arons, B., Binding, C., Chen, P., Donahue, J., Joseph, T. A., Koo, R., Romanow, A., Schmandt, C. and Yamamoto, W. (1989) "Collaboration technology research at Olivetti Research Centre.” Research report , Olivetti Research Centre, Menlo Park, California. (overview, conceptual) This paper describes the goals and premises behind the Olivetti Research Center's work in collaboration technology.

Lauwers, J. C., Joseph, T. A., Lantz, K. A. and Romanow, A. L. (1990a) "Replicated architectures for shared window systems: A critique." In Proceedings of the Conference on Office
Information Systems, p249-260, Boston, April 25-27.

(shared views, software design, evaluation) This paper documents the problems of replicated architectures used in shared window systems, and indicates how synchronization problems can be solved and how other limitations removed. The need for general systems support is addressed, and the advantages gained by making applications and servers "collaboration-aware" described.

Lauwers, J. C. and Lantz, K. A. (1990b)

"Collaboration awareness in support of collaboration transparency: Requirements for the next generation of shared window systems." In Proceedings of the ACM/SIGCHI Conference on Human factors in Computing, Seattle Washington, April 1-5, ACM Press. (shared views, critique) This report describes the problems/issues that existing shared window systems have come up against, and lists the requirements that the next generation of shared window systems should have. Issues addressed are: spontaneous interactions; workspace management; floor control; user customizability; annotation and telepointing; and performance.

Lazarov, G., Lilov, V. and Nikolova, M. (1990) "The 'User Illusion' method in multiuser interface design." In Proceedings of IFIP WG8.4 Conference on Multi-User Interfaces and Applications, Crete, S. Gibbs and A. A. VerrighnStuart (ed), North Holland.

Lea, M. and Spears, R. (1991) "Computer-mediated communication, deindividuation and group decision making." Int J Man Machine Studies, 34(2), p283-302, February. In the special edition on CSCW \& Groupware. Republished in Greenberg, 1991.

(decision support, evaluation) Technology changes the way people within a group behave. Lea and Spears discuss how computer-mediated communication affects deindividuation, the anonymity and loss of identity that occurs when people are submerged in a group. If deindividuation does exist, we would expect the social norms and constraints of people's behaviour to be weakened, which would have serious consequences on how decisions made by the group should be interpreted. The authors question past findings on how electronic communication changes the group's psychological states, and then present their own study and alternate view of the role of deindividuation.

Lederberg, J. and Uncapher, K. (1989) "Towards a national collaboratory." , The Rockefeller University, March 17-18.

(overview, social impact) This is a report of an invitational workshop whose mandate was to develop recommendations for a research agenda leading to a "National Collaboratory", a resource that would use networking and computer technology to support collaboration independent of distance and by increasing productive access to scarce and expensive 
assets. Definitely a "must read" for all those interested in the future directions of CSCW.

Lee, J. (1990a) "SIBYL: A tool for sharing knowledge in group decision making." In Proceedings of the Conference on Computer Supported Cooperative Work (CSCW'90), Los Angeles, California, October 7-10, ACM Press. (semi-structured messages, protocols, decision support, hypertext) SIBYL is a system that supports group decision making by representing and managing the qualitative aspects of the decisionmaking processes: alternatives, the goals to be satisfied, and the arguments evaluating the alternatives with respect to these goals. SIBYL is described and compared with other systems with similar objectives (eg gIBIS), and an example session provided. SIBYL is claimed to be a knowledge-based system which uses a semi-formal representation, whereas gIBIS is mainly a hypertext system with semantic types.

Lee, J. J. (1990b) "Xsketch: A multi-user sketching tool for X11." In Proceedings of the Conference on Office Information Systems, p169-173, Boston, April 25-27. (shared workspace, remote meetings, implementation) Lee describes work in progress on a multi-user sketching tool called xsketch.

Requirements and design goals are provided, plus details of the prototype implementation. A list of known problems, shortcomings and possible extensions are included.

Leland, M. D. P., Fish, R. S. and Kraut, R. E. (1988) "Collaborative document production using Quilt.” In Proceedings of the Conference on Computer-Supported Cooperative Work (CSCW '88), p206-215, Portland, Oregon, September 2628, ACM Press.

(data sharing, hypertext, implementation) Quilt is a tool for collaborative document production that emphasizes and supports the communication vital to good collaboration. For example, links may be structured hypermedia links that allow people to attach text and voice annotations to the document. These may be specialized as revision suggestions, public comments, and directed messages. The necessary coordination between collaborators is enhanced via activity logging, notification and triggering mechanisms. Access permissions can be set by the author to reflect the varying roles of collaborators (as writers, commenters, reviewers), while user-customizable definitions for such things as document and annotation types make the system both flexible and extensible.

Lewe, H. and Krcmar, H. (1990) "The CATeam meeting room environment as a human-computer interface." In Proceedings of IFIP WG8.4 Conference on Multi-User Interfaces and Applications, Crete, S. Gibbs and A. A. VerrighnStuart (ed), North Holland.

Lia, K.-Y. and Malone, T. W. (1988) “Object Lens: A 'spreadsheet' for cooperative work." In Proceedings of the Conference on Computer-
Supported Cooperative Work (CSCW'88), p115124, Portland, Oregon, September 26-28, ACM Press.

(semi-structured messages, hypertext) This paper introduces Object Lens, a second-generation version of their Information Lens. Object Lens contains two fundamental ideas. First, passive information can be represented as semi-structured objects, where each object is defined as part of an inheritance hierarchy, eg "Thing, Message, Action-request, Meetingproposal." By defining and modifying templates for these objects, users can represent and interact with many different kinds of information. Second, active rules for processing information are represented as semi-autonomous agents. When creating these agents, users specify rules for automatically processing information in different situations. A rule triggered by incoming news from a bulletin board may, for example, sort the interesting and topical news into appropriate folders, discarding the rest. With these two ideas, Object Lens integrates objectoriented databases, hypertext, and electronic messaging with intelligent routing.

Licklider, J. C. R. and Vezza, A. (1978)

"Applications of information networks."

Proceedings of the IEEE, 66(11), p1330-1346.

Reprinted in Greif, 1988.

(overview) This early paper briefly examines 30

"office of the future" applications and the network capabilities they require. Several political, social, and economic issues are then considered.

Lim, F. J. and Benbasat, I. (1991) "A communication-based framework for group interfaces in computer-supported collaboration." In Proceedings of the 24th Hawaii Conference on System Sciences, Kauai, Hawaii, January 8-11. (decision support) The paper presents a framework which outlines the various dimensions of communication in group interfaces. An analysis of communication flows is provided along four dimensions: concurrency, content, path, and channel.

Linde, C. (1988) "Who's in charge here? Cooperative work and authority negotiation in police helicopter missions." In Proceedings of the Conference on Computer-Supported Cooperative Work (CSCW '88), p52-64, Portland, Oregon, September 26-28, ACM Press.

(evaluation, social impact) Linde questions the common (and perhaps naive) assumption that the authority status of participants within an organization is fixed. Through extensive videotapes, she observed a flight officer and pilot on board a helicopter engaged in police missions. The pilot is responsible for all on-craft decisions, while the officer is responsible for the actual police mission. She observed a quite complex social structure. In particular, the "authority status" of crew members was subject to moment to moment negotiations, invoked as a normal, unremarked background condition of the ongoing daily operations. Linde suggests that negotiating authority is quite common in most collaborative work, and that it would be a mistake to 
rely only upon the formal organizational hierarchy when deciding upon the authority of participants.

Lison, H. and Crowley, T. (1989) "Sight and Sound." Unix Review, 7(10), p76-86.

(remote meetings, shared views, multimedia, implementation) This paper describes the BBN/Slate package

Losada, M., Sanchez, P. and Noble, E. E. (1990)

"Collaborative technology and group process feedback: Their impact on interactive sequences in meetings." In Proceedings of the Conference on Computer Supported Cooperative Work (CSCW '90), Los Angeles, California, October 7-10, ACM Press.

(face-to-face meetings, evaluation, social impact) The authors analyzed group collaborative behaviour by detecting patterns of interactive sequences in face to face meetings using time series analysis (the room used was the Capture Lab). If group process feedback is given to people participating in a computersupported meeting, the number of socio-emotional interactive sequences increases significantly above the expected level. With no feedback, the level is substantially less than the expected. The findings have implications for the efficient use of computer technology in terms of maximizing its collaborative potential.

Louie, G., Mantei, M. and Sellen, A. (1991)

"Making contact in a multi-media environment." Research Report, Dept of Computer Science, University of Toronto, Toronto, Ontario, February 2. Presented at the Ann Arbor HCI Consortium on Computer Supported Cooperative Work. (remote meetings)

Lowe, D. (1986) "SYNVIEW: The design of a system for cooperative structuring of information." In Proceedings of the Conference on Computer-Supported Cooperative Work (CSCW '86), p376-386, Austin, Texas, December 3-5, ACM Press.

(decision support) The SYNVIEW system implements cooperative structuring of information through an explicit representation for debate between the users of the system and through a voting mechanism for resolving disputes.

Lu, I. and Mantei, M. (1991) "Idea management in a shared drawing tool." Research report, Dept of Computer Science, University of Toronto, Toronto, Canada. Submitted to EC-CSCW '91. (shared workspace)

Lubich, H. and Plattner, B. (1990) “A proposed model and functionality definition for a collaborative editing and conferencing facility." In Proceedings of IFIP WG8.4 Conference on MultiUser Interfaces and Applications, Crete, S. Gibbs and A. A. Verrighn-Stuart (ed), North Holland.

Lutz, E., v. Kleist-Retzow, H. and Hoernig, K. (1990) "MAFIA - An active mail-filter-agent for an intelligent document processing support." In Proceedings of IFIP WG8.4 Conference on Multi-
User Interfaces and Applications, Crete, S. Gibbs and A. A. Verrighn-Stuart (ed), North Holland.

Lynch, K. J., Snyder, J. M., Vogel, D.R. and McHenry, W. K. (1990) "The Arizona Analyst Information System: Supporting collaborative research on international technological trends." In Proceedings of IFIP WG8.4 Conference on MultiUser Interfaces and Applications, Crete, S. Gibbs and A. A. Verrighn-Stuart (ed), North Holland.

Mack, L. A. (1989) "Technology for computersupported meetings." In Human Factors Society 33rd Annual Meeting, p857-861.

Mackay, W. (1988) "More than just a communication system: Diversity in the use of electronic mail." In Proceedings of the Conference on ComputerSupported Cooperative Work (CSCW '88), p344353, Portland, Oregon, September 26-28, ACM Press.

(email, evaluation) Email users were studied and rated into several categories, each with quite different habits and objectives. Prioritizers concentrate on the problem of managing incoming messages. Archivers concentrate on archiving information for subsequent use, and delegators delegate mail by passing it on to others. Mackay's study indicates that mail use is strikingly diverse, and that designers of email should recognize this diversity by designing systems that provide flexibility over a wide range of users.

Mackay, W., Malone, T. W., Crowston, K., Rao, R., Rosenblitt, D. and Card, S. K. (1989) "How do experienced Information Lens users use rules?" In Proceedings of the ACM Conference on Human Factors in Computing Systems, Austin, Texas, April 30-May 4, ACM Press.

(email, asynchronous conferencing, evaluation) The Information Lens provides electronic mail users with the ability to write rules that automatically sort, select and filter their messages. This paper describes experiences of 13 volunteer users of the rules facility. In particular: people without significant computer experience can create and use rules; useful rules can be created based on the fields present in all messages; rules are used for both prioritizing and sorting messages; delete rules are used primarily to filter out messages from low-priority distribution lists.

Mackay, W. E. (1990) "Patterns of sharing customizable software." In Proceedings of the Conference on Computer Supported Cooperative Work (CSCW '90), Los Angeles, California, October 7-10, ACM Press.

(data sharing, organizational concerns, evaluation) The act of customizing software is generally viewed as a solitary activity that allows users to express individual preferences. In this study, users were found to actively share their customization files with each other, which allowed members of each organization to establish and perpetuate informally-defined norms of behaviour. A small percentage of people were responsible for most of the sharing: highly skilled software engineers who were the first to experiment with and to customize any new software; and 
'translators' who interpreted the needs of the rest of the organization and created customization files tailored to those needs (usually founded upon the customization files of the highly-skilled). Implications of the results are offered.

Mackay, W. E. and Tatar, D. G. (1989) "Special issue on video as a research and design tool." SIGCHI Bulletin, 21(2), October. (collection, video, evaluation) This special issue contains several articles on how video can be used as a research tool for collecting and analyzing data, and as a design tool

Malone, T. W. (1988) "What is Coordination Theory?" research report SSM WP \#2051-88, Sloan School of Management, MIT, Cambridge, Mass., February. Presented at the NSF Coordination Theory Workshop.

(conceptual) Coordination theory is the study of coordination ie how the activities of separate actors can be coordinated. Coordination theory is introduced, and its importance to "coordination technologies" (systems that help people coordinate their activities) is offered.

Malone, T. W. and Crowston, K. (1990) "What is Coordination Theory and how can it help design cooperative work systems?" In Proceedings of the Conference on Computer Supported Cooperative Work (CSCW '90), Los Angeles, California, October 7-10, ACM Press.

(conceptual) Coordination theory is the study of coordination ie how the activities of separate actors can be coordinated. Coordination theory is introduced, and its importance to "coordination technologies" (systems that help people coordinate their activities) is offered. Previous examples of coordination theory and CSCW are described.

Malone, T. W., Grant, K. R., Lai, K.-Y., Rao, R. and Rosenblitt, D. (1987) "Semi-structured messages are surprisingly useful for computersupported coordination." ACM Trans Office Information Systems, 5(2), p115-131, April. Reprinted in Greif, 1988. An earlier version was published in CSCW '86.

(semi-structured messages, implementation) This paper argues that using a set of semistructured message templates is surprisingly helpful in designing a variety of computer-based communication and coordination systems. The system provide aids for: 1) composing messages to be sent, 2) selecting, sorting and prioritizing messages that are received, 3) responding automatically to some messages, and 4) suggesting likely responses to other messages. The implementation, called "Information Lens" is described. An important paper.

Malone, T. W., Grant, K. R. and Turbak, F. A. (1986) "The Information Lens: An intelligent system for information sharing in organizations." In Proceeding of the SIGCHI Human Factors in Computing Systems, p1-8, Boston, Mass, April 13-17, Association for Computing Machinery. Reprinted in Olson (1989). (semi-structured messages) This paper describes Information Lens, an intelligent system to help people share and filter information communicated by computer-based messaging systems.

Malone, T. W., Grant, K. R., Turbak, F. A., Brobst, S. A. and Cohen, M. D. (1987a) "Intelligent information-sharing systems." Comm ACM, 30(5), p390-402, May.

(semi-structured messages, email) The Information Lens is a prototype intelligent informatin-sharing system that is designed to include no tonly good user interfaces for supporting the problem-solving activity of individuals, but also good organizational interfaces for supporting the problem-solving activities of groups.

Malone, T. W., Yates, J. and Benjamin, R. I. (1987b) "Electronic markets and electronic hierarchies." Comm ACM, 30(6), p484-497, June.

(conceptual) By reducing the costs of coordination, information technology will lead to an overall shift toward proportionately more use of markets---rather than hierarchies---to coordinate economic activity.

Malone, T. W., Yu, K. and Lee, J. (1989) "What good are semistructured objects? Adding semiformal structure to hypertext." Research report CCSTR \#102, SSM WP \#3064-89-MS, Sloan School of Management, Cambridge, Mass, June.

(semi-structured messages, hypertext,

implementation) This report suggests that adding semantic structure to hypertext nodes can provide significant benefits for summarizing the contents of objects and their relationships, and automatically searching and manipulating collections of objects. Object Lens is used as an example. The report also suggests that the objects should be semi-structured, instead of rigidly structured. An overview of Object Lens is provided.

Mamrak, S. A., Kaelbling, M. J., Nicholas, C. K. and Share, M. (1987) "A Software Architecture for Supporting the Exchange of Electronic Manuscripts." Comm ACM, 30(5), p408-414, May.

As electric-manuscript exchange becomes more prevalent, problems arise in translating among the wide variety of electronic representations. The optimum solution is a system that can support both the use and the creation of translation tools.

Mantei, M. (1988) "Capturing the Capture concepts: A case study in the design of computer-supported meeting environments." In Proceedings of the Conference on Computer-Supported Cooperative Work (CSCW '88), p257-270, Portland, Oregon, September 26-28, ACM Press.

(face-to-face meetings, shared views, evaluation, social impact) The Capture lab is a face to face meeting room that included a computer console for every participant and a shared electronic blackboard. Mantei discussed three seemingly trivial but ultimately important design decisions made: seating arrangements; inter-viewing distances between 
participants; and access protocols to the shared blackboard. Mantei's lesson is that CSCW is much more than software, and must also cover political, physical and social processes. Even a seemingly trivial detail can change the nature of meetings held in a room.

Mantei, M. (1989) “Observations of executives using a computer supported meeting environment." Decision Support Systems, 5, p153-166, June. (decision support, face-to-face meetings)

Mantei, M., Baecker, R. M., Sellen, A. J., Buxton, W. A. S. and Milligan, T. (1991) "Experiences in the use of a media space." In ACM SIGCHI Conference on Human Factors in Computing Systems, New Orleans, April 28-May 2, ACM Press.

(remote meetings, video, implementation) CAVECAT is a media space system that uses integrated video, audio, and computers to allow spatially and temporally separated individuals and groups to work together. The paper presents and summarizes initial use of CAVECAT, including unsolved technological obstacles encountered, and its psychological and social impact.

Mantei, M. M. (1988) “Groupware: Interface design for meetings.” Research report CMI-88-001, Center for Machine Intelligence, Ann Arbor, Michigan, February 28.

(face to face meetings, collection) This article provides the position taken by four panelists at a CHI '88 conference panel session: Suchman (Xerox), DeSanctis (U of Minnesota), Applegate (Harvard U.) and Jarvenpaa (U of Texas). Mantei introduces face to face meeting environments and asks several very interesting research questions.

Mantyla, R., Alasuvanto, J. and Hammainen, H. (1990) "PAGES: A testbed for groupware applications." In Proceedings of IFIP WG8.4 Conference on Multi-User Interfaces and Applications, Crete, S. Gibbs and A. A. VerrighnStuart (ed), North Holland.

Markus, M. L. and Connolly, T. (1990) "Why CSCW applications fail: Problems in the adoption of interdependent work tools." In Proceedings of the Conference on Computer Supported Cooperative Work (CSCW '90), Los Angeles, California, October 7-10, ACM Press. (critique, organizational concerns) This paper extends Grudin's 1988 study on why CSCW applications fail. In particular, failure occurs even when: there are no asymmetries between those who benefit from an application and those who do extra work; and decision makers do not confuse their own personal benefits with the collective benefit. The authors argue that failure may also be due to interdependence in the payoffs derived, where payoffs to one user may depend on the behaviour of others.

McCarthy, J. C. (1991) "An experimental study of common ground in text-based communication." In ACM SIGCHI Conference on Human Factors in
Computing Systems, New Orleans, April 28-May 2, ACM Press.

(remote meetings, evaluation) The paper describes an evaluation made of a real-time text-based communication system.

McCarthy, J. C. and Miles, V. C. (1990)

"Elaborating communication channels in conferencer." In Proceedings of IFIP WG8.4 Conference on Multi-User Interfaces and Applications, Crete, S. Gibbs and A. A. VerrighnStuart (ed), North Holland.

McCarthy, J. C., Miles, V. C., A.F., M., Harrison, M. D., Dix, A. J. and Wright, P. C. (1991) "Four generic communication tasks which must be supported in electronic conferencing." $A C M$ SIGCHI Bulletin, 23(1), p41-43, January. Poster presentation.

(remote meetings) Four generic communications tasks must be supported by electronic conferencing: synchronising communication; maintaining conversational coherence; repairing conversational breakdown; maintaining shared focus.

McDonnell, D. and Raymond, J. (1987) "Integration of the electronic blackboard and the electronic overhead projector." In The Second Guelph Symposium on Computer Conferencing, p193197, Guelph, Ontario, Canada, June 1-4, University of Guelph. (remote meetings, shared workspace) This paper describes a distance-education course-delivery system that uses a "real" electronic blackboard, slow-scan tv, an electronic overhead projector, and a fax machine. It is interesting in that it does not seem as workstation-based as the traditional systems seen in CSCW.

McGrath, J. E. (1990) "Time matters in groups.” In Intellectual Teamwork: Social Foundations of Cooperative Work, p23-62, J. Galegher, R. E. Kraut and C. Egido ed., Hillsdale, New Jersey, Lawrence Erlbaum Associates. (social impact) The paper provides a theoretical analysis of the small group. There are two themes. First, group functioning is multidimensional, and that the actions of individuals, groups and organizations have implications for outcomes on each of these dimensions. Second, the temporal sequence of behaviour in groups (stages of group development, phases of group task performance...) is both a function and a determinant of group effectiveness. The themes then provide the foundation for a speculative discussion of the effects of information technologies, and how they might help or hinder the temporal flow of communication and work in groups.

Minneman, S. L. and Bly, S. A. (1990) "Experiences in the development of a multi-user drawing tool." In The 3rd Guelph Syposium on Computer Mediated Communication, p154-167, Guelph, Ontario, Canada, May 15-17, University of Guelph Continuing Education Division. 
(shared workspace, evaluation, remote meetings) Authors describe Commune, a multi-user drawing tool that allows users collaborating remotely to share a common drawing surface. The system is described and early observations of use provided.

Minneman, S. L. and Bly, S. A. (1991) "Managing a trois: A study of a multi-user drawing tool in distributed design work." In ACM SIGCHI Conference on Human Factors in Computing Systems, New Orleans, April 28-May 2, ACM Press.

(shared workspace, video, evaluation, remote meetings) The authors evaluate a multi-user drawing tool called Commune (including video link) in a three-person distributed design exercise. Tool use was augmented by a video/audio link and audio only. They observed no difficulties in 3 people over 2 people using the shared drawing surface use.

MIT (1983a) “Talking heads.” In Discursions, Boston, Mass, Architecture Machine Group, MIT. Optical disc.

(remote meetings) A video of what is perhaps the best-realized telepresence remote conferencing system. Once described as a "very scary system" by a person involved in its design.

MIT (1983b) "Zero bandwidth video." In Discursions, Boston, Mass, Architecture Machine Group, MIT. Optical disc.

(remote meetings) A video of a telepresence remote conferencing system. Rather than sending a video image down the wire, this version uses a speech recognizer to animate images of participants in a video conference.

Moran, T. P. and Anderson, R. J. (1990) "The workaday world as a paradigm for CSCW design." In Proceedings of the Conference on Computer Supported Cooperative Work (CSCW'90), Los Angeles, California, October 7-10, ACM Press. (conceptual, critique, multi-media) Xerox EuroPARC is developing an integrated multi-media environment as an integral part of its formal and informal working environment. The authors suggest from their initial experiences with this kind of technology that it exhibits qualitatively different properties, which seem to call into question many of our ideas about what computer systems are and how people relate to them.A paradigm called the "Workaday World" is offered, that distinguishes between technology, sociality, and work practice. EuroPARC's multi-media environment is discussed within this paradigm.

Murrel, S. (1983) "Computer communication system design affects group decision making." In Proceedings of the ACM/SIGCHI Human Factors in Computing Systems, p63-67, Boston, December 12-15.

(remote conferencing, protocols, evaluation, decision support) This research explored the impact of two synchronous systems which vary in the role of immediacy of interaction and feedback on group decision making. One system is message-oriented, requiring a conferee to complete a message before interacting with others. The other displays what each group member is typing as it is typed in a separate window on the screens of all participants. Groups were asked to solve a problem. All groups produced decisions superior to the average initial individual solutions. Window system groups improved more, produced significantly higher quality decisions, and spent less time discussing how to organize the system and task efforts.

Nardi, B. A. and Miller, J. R. (1990) “An ethnographic study of distributed problem solving in spreadsheet development." In Proceedings of the Conference on Computer Supported Cooperative Work (CSCW '90), Los Angeles, California, October 7-10, ACM Press.

(evaluation, social impact) A shorter version of Nardi and Miller's 1991 Int J Man Machine Studies article.

Nardi, B. A. and Miller, J. R. (1991) "Twinkling lights and nested loops: Distributed problem solving and spreadsheet development." Int J Man Machine Studies, 34(2), p161-184, February. In the special edition on CSCW \& Groupware. Republished in Greenberg, 1991. (evaluation, social impact) Nardi and Miller's ethnographic study is on spreadsheets, long considered a good example of a well designed "single user" application. Much to their surprise, they observed that spreadsheet co-development was the rule, not the exception. They saw a high degree of cooperation in sharing program expertise; transferring domain knowledge; debugging; training; and face to face work in meetings. The general implication is that cooperative work happens all the time, in spite of the inherent limitations of the software.

Neches, R. (1988) "Tools help people cooperate only to the extent that they help them share goals and terminology." ACM Trans Office Information Systems, 6(3). An earlier version was published in CSCW '86.

This paper describes two pieces of work on support tools: one for the construction of consistent and principled human-computer interfaces and the other for the construction of AI knowledge bases. The knowledge-based approach to interface construction illustrates how it would apply to detecting design conflicts and inconsistencies stemming from two different kinds of team communication failure.

Neuwirth, C. M., Kaufer, D. S., Chandhok, R. and Morris, J. (1990) "Issues in the design of computer support for co-authoring and commenting." In Proceedings of the Conference on Computer Supported Cooperative Work ( $\left.C S C W^{\prime} 90\right)$, Los Angeles, California, October 710, ACM Press.

(data sharing, hypertext, implementation) The paper reports on a project to develop a "work in preparation" editor, or PREP editor, to study coauthoring and commenting relationships. Three issues in designing computer support for coauthoring and commenting were identified: support for social interaction; support for cognitive aspects of co-authoring and external commenting; and 
support for practicality in both types of interaction. The approach taken by the PREP editor is described.

Newman, D. (1988) "Sixth graders and shared data:

Designing a LAN environment to support

collaborative work." In Proceedings of the

Conference on Computer-Supported Cooperative

Work (CSCW '88), p291-305, Portland, Oregon, September 26-28, ACM Press.

(education, evaluation) This paper describes the Earth Lab project--a computer-supported collaboration on a science project between sixth graders. Students were seen to use the social organization of the classroom activities as a frame of reference.

Nielson, J. (1987) “Computer supported cooperative work: Trip report.” ACM/SIGCHI Bulletin, 19(1), p54-61.

(report) A review of the $\mathrm{CSCW}$ '86 conference.

Nylund, A. (1989) "Aspects of cooperation in a distributed problem solving environment." In Proceedings of the 1st European Conference on Computer Supported Cooperative Work (ECCSCW '89), Gatwick, U.K., September 13-15, Computer Sciences House, Sloug, UK.

Olson, G. (1989) "The nature of group work." In Human Factors Society 33rd Annual Meeting, p852-856.

Olson, G. P. and Atkins, D. E. (1990) "Supporting collaboration with advanced multimedia electronic mail: The NSF EXPRES project." In Intellectual Teamwork: Social Foundations of Cooperative Work, p429-452, J. Galegher, R. E. Kraut and C. Egido ed., Hillsdale, New Jersey, Lawrence Erlbaum Associates.

(email, multimedia) A specific example of coauthorship is the joint planning, writing, and submission of research proposals to funding agencies. In the paper world, the document will include scotch-taped text, figures, tables, notes, and so on. The NSF EXPRESS email system supports this model by allowing co-authors to bundle together text, outlines, graphics, and spreadsheets into a single electronic document.

Olson, J. S., Olson, G. M., Mack, L. A. and Wellner, P. (1990) "Concurrent editing: The group's interface." In Proceedings of Interact '90, p834-840, D. Diaper et al (ed), Elsevier Science Publishers B.V.

An issue-raising article on concurrent text editing activity.

Olson, M. H. (1989) Technological support for work group collaboration, Lawrence Erlbaum Associates, Hillsdale, New Jersey. (collection) Titles in this collection include: 1) User approaches to computer-supported teams. Johansen.

2) Assumptions underlying systems that support work group collaboration. Dhar \& Olson. 3) How is work coordinated? Implications for computer-based support. Johnson.
4) The information lens: An intelligent system for information sharing and coordination. Malone, Grant, Lai, Rao \& Rosenblitt.

5) Flexible interactive technologies for multi-person tasks: Current problems and future prospects. Bikson, Eveland, Gutek.

6) Organizational architecture for distributed computing: The next frontier in system design. Pava.

7) Developing the management systems of the 1990s: The role of collaborative work. Cashman \& Stroll.

8) Toward portable ideas. Stefik \& Brown.

9) A method for evaluating work group productivity products. Floyd \& Turner.

Olson, M. H. and Bly, S. A. (1991) "The Portland Experience: A report on a distributed research group." Int J Man Machine Studies, 34(2), p211228 , February. In the special edition on CSCW \& Groupware. Republished in Greenberg, 1991. (remote meetings, virutal hallways, video, evaluation) Xerox developed a cross-site environment called Media Space---a network of video, audio, and computing technologies---to connect two distance separated research laboratories: the large Palo Alto lab and a much smaller site in Portland. The Portland laboratory was intensionally developed to force its group to focus on interpersonal computing in a geographically distributed organization (ie to keep in close touch with Palo Alto). This paper summarizes observations of the Portland experience made by an outside observer. Insight into remote work in a distributed organization is provided and the use of the collaborative tools discussed.

Opper, S. (1988) “A groupware toolbox.” Byte, December.

(implementation) Opper provides a catalog of commercially available groupware products. Some of her topics include: document editing, forms centered applications (coordination), team development and workgroup communication management.

Orr, J. (1986) "Narratives at work: Story telling as cooperative diagnostic activity." In Proceedings of the Conference on Computer-Supported Cooperative Work (CSCW'86), p62-72, Austin, Texas, December 3-5, ACM Press.

(social impact) The diagnostic process for copiers involves narration of the process, including a description of the state of the machine. This follows from the fact that the problem in diagnosis is not so much the testing of components as keeping track of the tests and making sense of their results. The anecdotal re-telling of this narrative to one's associates constitutes the mechnaism for incorporating the diagnostic experience into the community expertise.

Patterson, J. F., Hill, R. D., Rohall, S. L. and Meeks, W. S. (1990) "Rendezvous: An architecture for synchronous multi-user applications." In Proceedings of the Conference on Computer Supported Cooperative Work (CSCW 
'90), Los Angeles, California, October 7-10, ACM Press.

(software design, implementation) Rendezvous is an architecture for creating synchronous multi-user applications. It consists of two parts: a run-time architecture for managing the multi-user session (based on a UIMS), and a start-up architecture for managing the network connectivity.

Pendergast, M. O. and Vogel, D. (1990) "Design and implementation of a PC/LAN-based multi-user text editor." In Proceedings of IFIP WG8.4 Conference on Multi-User Interfaces and Applications, Crete, S. Gibbs and A. A. VerrighnStuart (ed), North Holland.

Pettersson, E. (1989) “Automatic information processes in document reading. A study of information handling in two intensive care units." In Proceedings of the 1st European Conference on Computer Supported Cooperative Work (ECCSCW '89), Gatwick, U.K., September 13-15, Computer Sciences House, Sloug, UK.

Piturro, M. C. (1989) "Computer conferencing: Brainstorming across time and space." Management Review, p43-50, August. (asynchronous conferencing, overview, implementation) This popular article introduces asynchronous computer conferencing. It describes how to get started, lists several success stories and lists the commercial products available.

Pliskin, N. (1989) "Interacting with electronic mail can be a dream or a nightmare: a user's point of view." Interacting with Computers, 1(3), p259272, December. (email, evaluation) BITNET email encounters are reviewed from a users point of view. Interaction difficulties such as addressing problems, unreliability issues, medium limitations and interface problems are raised.

Poole, M. S., Homes, M. and DeSanctis, G. (1988) "Conflict management and group decision support." In Proceedings of the Conference on Computer-Supported Cooperative Work (CSCW '88), p227-243, Portland, Oregon, September 2628, ACM Press.

(evaluation, decision support, evaluation) This paper discusses group decision support systems (GDSS) and conflict management. The authors contrast three groups: those with computer supported GDSS, those with a manual GDSS, and those with neither.

Posner, I., Baecker, R. and Mantei, M. (1991) "How people write together." Research report, Dept of Computer Science, University of Toronto, Toronto, Canada. Submitted to EC-CSCW '91.

Postel, J. B., Finn, G. G., Katz, A. R. and Reynolds, J. K. (1988) "An Experimental Multimedia Mail System.” ACM Trans Office Information Systems, 6(1), p63-81, January. (email, multimedia, implementation) An experimental multimedia mail system that allows the user to read, create, edit, send, and receive messages containing text, images, and voice is discussed.
Powrie, S. E. and Siemieniuch, C. E. (1990) "IBC and cooperative working in the automotive industry." In Proceedings of IFIP WG8.4 Conference on Multi-User Interfaces and Applications, Crete, S. Gibbs and A. A. VerrighnStuart (ed), North Holland.

Prinz, W. and Pennelli, P. (1989) "Relevance of the X.500 directory to CSCW applications: Directory support for computer based group communication." In Proceedings of the 1st European Conference on Computer Supported Cooperative Work (EC-CSCW '89), Gatwick, U.K., September 13-15, Computer Sciences House, Sloug, UK.

Quinn, R. (1990) "A coordination environment: A new way of working together." Product blurb , Coordination Technology, Inc, 35 Corporate Dr, Trumbull, Conneticut.

(implementation, protocols) This paper gives some background to "Together", a commercial product that allows people to coordinate their activities through a "coordination environment".

Reder, S. and Schwab, R. G. (1988) "The communicative economy of the workgroup: Multi-channel centres of communication." In Proceedings of the Conference on ComputerSupported Cooperative Work (CSCW '88), p354368 , Portland, Oregon, September 26-28, ACM Press.

(social impact, critique) There are many channels of communication available to people within a work group. As a consequence, a CSCW system will assume a variety of socio-functional niches, competing with other electronic or traditional communications systems. When multiple communication channels are available, people should be expected to---and will--switch between them. The authors argue that the choice of the communication channel and the switching between them are a natural part of a person's communication strategies and tactics, and must be considered when installing a new CSCW system in the workplace.

Reder, S. and Schwab, R. G. (1990) "The temporal structure of cooperative activity." In Proceedings of the Conference on Computer Supported Cooperative Work (CSCW '90), Los Angeles, California, October 7-10, ACM Press. (organizational concerns, evaluation) The research considers the relationship between individual work and group work activity. In particular, it asks how the characteristic temporal and spatial patterning of behaviour in the work environment relates to the modes of cooperative behaviour. A theoretical framework is suggested, that begins with the observation that individuals in office settings must routinely resolve conflicts between having uninterrupted periods of time in which to get their own work done, and being accessible for communication with others with whom they work.

Rein, G. L. and Ellis, C. A. (1989) "The NICK experiment reinterpreted: Implications for 
developers and evaluators of groupware." Office: Technology and People, 5(1).

(face-to-face meetings, evaluation) The Nick experiment was an empirical study conducted to explore and increase the understanding of prototype meeting support technology usage by software design teams working on unstructured, high-level design problems. The paper interprets the experimental data, and accounts for interactions among the three main effects of technology, team and task. The salient findings were: 1) the electronic messaging facility emerged as a potentially effective way for group members to attain more equality and to influence the direction of the meetings; and 2) group focus and attention on completing the task was increased for groups using an electronic blackboard.

Rein, G. L. and Ellis, C. A. (1991) "rIBIS: A realtime group hypertext system." Int J Man Machine Studies, 34(3), p349-368, March. In the special edition on CSCW \& Groupware. Republished in Greenberg, 1991.

(data sharing, hypertext, remote meetings, implementation) Hypertext developers now recognize that hypertext documents will be used and updated by large groups of people. This paper takes the next logical step by combining both real-time with asynchronous hypertext manipulation in their rIBIS system. An rIBIS session is a distributed meeting where participants can be in a "tightlycoupled" or "loosely-coupled" mode. In the first, tightly-coupled members all see the same thing, and take turns controlling and manipulating the hypertext display. In the second, a person works semi-privately by editing a portion of the hypertext-only large-grained changes are broadcast to other members. The result is a system valuable not only for storing information, but also for allowing people to actively capture and structure critical aspects of a meeting process.

Rice, R. E. and Shook, D. E. (1990) "Voice messaging, coordination, and communication." In Intellectual Teamwork: Social Foundations of Cooperative Work, p327-350, J. Galegher, R. E. Kraut and C. Egido ed., Hillsdale, New Jersey, Lawrence Erlbaum Associates. (email, multimedia, evaluation, organizational concerns) Voice mail is shown to have advantages similar to email. In addition, voice mail provides a channel that makes it possible to communicate the emotional intensity of the message as well as its substantive content. The effect of task complexity and peer/supervisor relationships on voice mail use is also raised.

Rodden, T. and Sommerville, I. (1989) "Building conversations using mailtrays." In Proceedings of the 1st European Conference on Computer Supported Cooperative Work (EC-CSCW '89), Gatwick, U.K., September 13-15, Computer Sciences House, Sloug, UK.

Root, W. R. (1988) "Design of a multi-media vehicle for social browsing." In Proceedings of the Conference on Computer-Supported Cooperative
Work (CSCW '88), p25-38, Portland, Oregon, September 26-28, ACM Press.

(virtual hallways, video) This paper focuses explicitly on tools to enable unplanned, informal social interaction through a "social interface" which provides direct, low-cost access to other people through the use of multi-media communications channels. A prototype desktop browser called "Cruiser" is described.

Sarin, S. and Greif, I. (1985) "Computer-based realtime conferencing systems." IEEE Computer, 18(10), p33-45. Reprinted in Greif, 1988. (shared views, shared workspace, remote meetings, implementation) This paper discusses design tradeoffs for shared workspaces in a remote conferencing setting. Several example systems are described. Mblink is a shared bitmap system, and RTCAL builds a shared workspace of information from participants' on-line calendars.

Sathi, A., Morton, T. E. and Roth, S. F. (1986) "Callisto: An intelligent project management system." AI Magazine, p34-52, Winter. Reprinted in Greif, 1988.

(implementation) Callisto is a project management system for building large engineering prototypes. It facilitates the documentation of the expertise related to the prototyping effort so that it can be transferred to future projects.

Scott, P. D. (1988) "Formal models of protocols for computer supported meetings." Research report CMI-88-002, Center for Machine Intelligence, Ann Arbor, Michigan, February 29.

(face to face meetings, protocols) This paper introduces turntaking protocols used by people at face to face meetings and how software should represent those protocols. The thrust is the set of formal specifications Scott uses to represent the protocols

Sheffield, J. (1989) “The Effects of Bargaining Orientation and Communication Medium on Negotiations in the Bilateral Monopoly Task: A Comparison of Decision Room and Computer Conferencing Communication Media." In ACM/SIGCHI Conference on Human Factors in Computing Systems, p43-48, Austin, Texas. (decision support, asynchronous conferencing, evaluation) Pairs of subjects with either a competitive or an integrative bargaining orientation completed the Bilateral Monoploy Task in one of four communication media: text-only, text plus visual access, audio-only, and audio plus visual access. The audio mode led to a higher joint outcome. The support for negotiation offered by decision room and computer conferencing technologies is compared based on the efficiency and richness of the communication media available in each.

Shepherd, A., Mayer, N. and Kuchinsky, A. (1990) "Strudel -- An extensible electronic conversation toolkit." In Proceedings of the Conference on Computer Supported Cooperative Work (CSCW '90), Los Angeles, California, October 7-10, ACM Press. 
(semi-structured messages, protocols, implementation) Authors describe the conceptual model of Strudel, a toolkit of generic components for conversation and action management. To empower work groups to more effectively conduct their computer-based communication, coordination, and information sharing activities, Strudel packages within a simple model of task and action the semistructured message, active message and conversation management paradigms. To facilitate acceptance and use within varying work cultures, the model is defined in terms of a set of extensible components.

Singer, J., Behrend, S. and Roschelle, J. (1988)

"Children's collaborative use of a computer microworld." In Proceedings of the Conference on Computer-Supported Cooperative Work (CSCW '88), p271-281, Portland, Oregon, September 2628, ACM Press.

(education, evaluation) This paper discusses a framework and methodology for understanding the use of computers in collaborative learning. The system used is the "Envisioning machine," where students learn by communicating their ideas and coordinating their actions.

Smith, H. T., Hennessy, P. A. and Lunt, G. (1989)

"The activity model environment: An object oriented framework for describing organisational communication." In Proceedings of the 1st European Conference on Computer Supported Cooperative Work (EC-CSCW'89), Gatwick, U.K., September 13-15, Computer Sciences House, Sloug, UK.

Smith, R. B. (1988) "A prototype futuristic technology for distance education (working draft)." In NATO Research Workshop on New Directions in Education Technology, Cranfield, England, November.

(education, virtualworlds, video) The shared alternate reality kit is described as a prototype for distance education. The system is based on a shared world model. Users may roam around, encountering each other to act together in a collaborative task while communicating over an audio-video link. Motivations, visions and issues are described.

Smith, R. B., O'Shea, T., O'Malley, C., Scanlon, E. and Taylor, J. (1989) "Preliminary experiences with a distributed, multi-media,problem environment." In Proceedings of the 1st European Conference on Computer Supported Cooperative Work (EC-CSCW'89), Gatwick, U.K., September 13-15, Computer Sciences House, Sloug, UK.

Sproull, L. and Kiesler, S. (1986) "Reducing social context cues: Electronic mail in organizational communication." Management Science, 32(11), p1492-1512. Reprinted in Greif, 1988. (email, evaluation, social impact) This paper describes an empirical study on email, particularly on the effects of email's limited social context cues. This lack of cues is an advantage and disadvantage, depending upon the situation.
Stanchev, P. and Sabev, V. (1990) "CNLS Computer Network Lecturing System." In Proceedings of IFIP WG8.4 Conference on MultiUser Interfaces and Applications, Crete, S. Gibbs and A. A. Verrighn-Stuart (ed), North Holland.

Stasz, C. and Bikson, R. (1986) "Computersupported cooperative work: Examples and issues in one federal agency." In Proceedings of the Conference on Computer-Supported Cooperative Work (CSCW '86), p318-324, Austin, Texas, December 3-5, ACM Press.

(critique) This paper disucsses five issues as examples of the kinds of issues that organizations may face in their attempts to successfuly implement computersupported work: training, dissemination, hierarchical vs network communications, centralized vs decentralized decision making, and work sharing between different technologies and systems.

Stefik, M., Bobrow, D. G., Foster, G., Lanning, S. and Tatar, D. (1987a) "WYSIWIS revised: Early experiences with multiuser interfaces." $A C M$ Trans Office Information Systems, 5(2), p147167, April. An earlier version appeared in CSCW '86.

(face-to-face meetings, shared workspace, idea processor,) WYSIWIS (What You See Is What I See) is a foundational abstraction for multiuser interfaces that expresses many of the characteristics of a chalkboard in face to face meetings. This excellent paper describes two WYSIWIS systems used in CoLab. Boardnoter imitates a chalkboard, while Cognoter is a multi-person ideas processor. The design issues encountered are described (particularly in problems dealing with multiple windows and focii of attention), along with their tentative solutions.

Stefik, M., Foster, G., Bobrow, D., Kahn, K., Lanning, S. and Suchman, L. (1987b) "Beyond the chalkboard: Computer support for collaboration and problem solving in meetings." Comm ACM, 30(1), p32-47. Reprinted in Greif, 1988.

(shared workspace, implementation) This paper describes CoLab, a shared workspace for face to face meetings. Three systems are described: Boardnoter (an electronic chalkboard), Cognoter (a multi-person ideas processor), and Argnoter (an argumentation spreadsheet for proposals). Conceptual and programming issues are described as well.

Stevens, C. H. (1986) "Electronic organization and expert networks: Beyond electronic mail and computer conferencing." Working paper 90s:86021, Sloan School of Management, Massachusetts Institute of Technology, Cambridge, Massachusetts, May.

Storrs, G. (1989) "Group working in the DHSS Large Demonstrator Project." In Proceedings of the 1st European Conference on Computer Supported Cooperative Work (EC-CSCW '89), Gatwick, U.K., September 13-15, Computer Sciences House, Sloug, UK. 
Stults, R. (1988) "Experimental uses of video to support design activities." Xerox PARC, Palo Alto, California.

(remote meetings, virtual worlds, video) This report provides the origins and description of four projects that used video to support design activity. These are: a) the distributed design studio; b) the cross-site workspace; c) studio with design journal; and d) the office design project.

Suchman, L. and Trigg, R. (1986) “A framework for studying research collaborations." In Proceedings of the Conference on Computer-Supported Cooperative Work (CSCW '86), p221-228, Austin, Texas, December 3-5, ACM Press. (evaluation) This paper describes a methodological and topical framework for studying collaboration in research settings. The framework is intended to capture the central activities and issues in research collaboration, and to represent them in a way that can inform the design of computer support. The starting premises for studying collaboration are presented, the use of qualitative ad naturalistic methods described, and preliminary findings reported.

Suomi, R. (1989) "Inter-organisational information systems as a tool for computer-supported cooperative work." In Proceedings of the 1st European Conference on Computer Supported Cooperative Work (EC-CSCW'89), Gatwick, U.K., September 13-15, Computer Sciences House, Sloug, UK.

Suzuki, T., Taniguchi, H. and Takada, H. (1986) "A real-time electronic conferencing system based on distributed Unix." In Proceedings of the Usenix 1986 Summer Conference, p189-199, Atlanta, Georgia, June 9-13.

(shared views, implementation) This paper describes a real-time electronic conferencing service constructed on distributed Unix. Identical contents are displayed in windows on each participant's work station and updated simultaneously. Any Unix service can be run without any modification. Some mechanisms included are access-rights, shared cursor, and a voice channel through a parallel PBX system.

Tang, J. (1990) "Observations on the use of shared drawing spaces." Videotape , Xerox PARC, Palo Alto, California.

(shared workspace) The videotape uses clips of small group design meetings to illustrate how people collaborate through shared drawing spaces. Clear and convincing.

Tang, J. C. and Minneman, S. L. (1991) "VideoWhiteboard: Video shadows to support remote collaboration." In ACM SIGCHI Conference on Human Factors in Computing Systems, New Orleans, April 28-May 2, ACM Press. (remote meetings, video, implementation)

Tang, J. C. (1989) "Listing, drawing, and gesturing in design: A study of the use of shared workspaces by design teams." PhD thesis, Department of Mechanical Engineering, Stanford University,
California, April. Also available as research report SSL-89-3, Xerox Palo Alto Research Center, Palo Alto, California.

(shared workspace, evalution) This dissertation is a descriptive study of the shared workspace activity of small groups working on conceptual design tasks, activities that include listing, drawing and gesturing. The paper presents: a methodology for observing and analyzing collaborative design activity; a detailed description and analysis of key aspects of shared workspace activity; a set of specific recommendations for the design of tools to support shared workspace activity. This thesis is required reading for the designer of a shared workspace.

Tang, J. C. (1991) "Findings from observational studies of collaborative work." Int J Man Machine Studies, 34(2), p143-160, February. In the special edition on CSCW \& Groupware. Republished in Greenberg, 1991.

(shared workspace, evaluation) This paper is an expanded version of Tang and Leifer's 1988 paper. The work activity of small groups of 3 to 4 people was videotaped and analysed in order to understand collaborative work and to guide the development of their listing, drawing, gesturing, and talking around a shared drawing surface. The result is a set of design implications for tools that support shared workspace activity.

Tang, J. C. and Leifer, L. J. (1988) “A framework for understanding the workspace activity of design teams." In Proceedings of the Conference on Computer-Supported Cooperative Work (CSCW '88), p244-249, Portland, Oregon, September 2628, ACM Press.

(shared workspace, evaluation) Tang and Leifer used detailed transcripts of design sessions to examine the possible purposes behind activities of a small design team who share a drawing surface. They found that artifacts, when combined with a person's gestures, are just as valuable for representing ideas and for engaging attention. A graphic evolves along with ideas into a final artifact, and gesturing is used for pointing and focusing attention during the collaboration. They conclude that too much attention has been paid to the artifacts left behind from collaborative meetings. In many cases, these are just marks that are inherently meaningless. The process of creating drawings and gesturing to them may be as important to the design process as the drawings themselves.

Tang, J. C. and Minneman, S. L. (1990) "Videodraw: A video interface for collaborative drawing." In ACM SIGCHI Conference on Human Factors in Computing Systems, p313-320, Seattle Washington, April 1-5, ACM Press. (shared workspace, implementation) This paper describes the empirical foundations and the implementation of VideoDraw, a video-based multiuser sketchpad supporting remote collaboration.

Tarazi, M. H. (1989) "Object sharing in a multi-user hypertext system.” MSc Thesis CCS TR\#101, 
Center for Coordination Science, MIT, Cambridge, Massachusetts, June 1990.

(hypertext, implementation, software design) Objectsharing requirements are described for the Object Lens system, which integrates features of hypertext, object-oriented systems, and rule-based agents. Approaches to object-sharing are evaluated, and a new scheme initiated through email exchange is promoted. Although most of the discussion is specific to Object Lens, the ideas are important for general multi-user interface toolkit construction.

Tatar, D. G., Foster, G. and Bobrow, D. G. (1991) "Design for conversation: Lessons from Cognoter." Int J Man Machine Studies, p185-210, February. In the special edition on CSCW \& Groupware. Republished in Greenberg, 1991. (idea processors, shared workspace, evaluation) Users encountered unexpected communicative breakdowns when using Cognoter, a multi-user idea organizing tool. Difficulties stemmed from an incorrect model of conversation implicit int the software's design. A more realistic model of the user situation was created, and the tool redesigned.

Thimbleby, H., Anderson, S. and Witten, I. H. (1990) "Reflexive CSCW: Supporting long-term personal work." Interacting with Computers, 2(3), p330-336.

(conceptual, data-sharing, social impact) The paper argues that the plight of the individual user can be viewed as a CSCW problem, for the individual frequently acts as multiple persona performing many independant tasks, perhaps in several places. "Reflexive CSCW" is proposed as a CSCW system applicable to personal work.

Thomas, R. H., Forsdick, H. C., Crowley, T. R., Schaaf, R. W., Tomlinson, R. S., Travers, V. M. and Robertson, G. G. (1985) "Diamond: A Multimedia Message System Built on a Distributed Architecture." IEEE Computer, 18(12), p65-78. Reprinted in Greif, 1988. (multimedia, email) Diamond is a multimedia, electronic mail/document system that supports text, graphics, images, speech, and structured documents. The user interface and architecture are described.

Trigg, R., Suchman, L. and Halasz, F. (1986) "Supporting collaboration in NoteCards." In Proceedings of the Conference on ComputerSupported Cooperative Work (CSCW'86), p153162, Austin, Texas, December 3-5.

(hypertext, idea processors) This paper focuses on experience with and extensions to NoteCards, a hypertext-based idea structuring system. The forms of collaboration discussed include draft-passing, simultaneous sharing and online presentations. The requirement that mutual intelligibility be maintained between collaborators leads to the need for support of annotative and procedural as well as substantive activities.

Trigg, R. H. (1988) “Guided tours and tabletops: Tools for communicating in a hypertext environment." In Proceedings of the Conference on Computer-Supported Cooperative Work
( $C S C W$ '88), p216-226, Portland, Oregon, September 26-28, ACM Press. Reprinted in Greif, 1988.

(hypertext) Trigg, the creator of the Xerox Notecards hypertext system, tackles the "lost in hyperspace" problem--the difficulty of navigating through complex hypertext networks. Unlike sequential documents, the rich inter-connections in hypertext may make it difficult for the unguided reader to follow paths preferred by the author (eg introductory tours through the document). Trigg introduces two new Notecard techniques to ameliorate this problem: tabletops and guided tours. A tabletop records a specific set of notecards (hypertext fragments) and their layout on a screen. A guided tour is a graphical interface that allows one to navigate between tabletops. Normal notecards can further supplement a tour by pointing to and annotating other cards on the tabletop. In this way, an author can "guide" the reader through the text.

Tueni, M. and Li, J. (1989) "Knowledge-based office automation and CSCW." In Proceedings of the 1st European Conference on Computer Supported Cooperative Work (EC-CSCW'89), Gatwick, U.K., September 13-15, Computer Sciences House, Sloug, UK.

UniversityOfGuelph (1987) The second Guelph symposium on computer conferencing, University of Guelph, Guelph, Ontario, Canada, June 1-4.

(collection, remote meetings, asynchronous conferencing, education) The Guelph symposium concentrated mostly on remote and asynchronous conferencing, and people's experiences in using it. Papers were presented in several sections. 1. Distance and adult education; 2. Socio-psychological issues; 3. Computer conferencing applications; 4. General educational issues; 5. Electronic conferencing and beyond; 6. Electronic message interchange; and 7. Research applications of computer conferencing.

UniversityOfGuelph (1990) The third Guelph symposium on computer mediated communication , University of Guelph, Continuing Education Division, Guelph, Ontario, Canada, May 15-17. (collection) The Guelph symposium contains several parts and sections. Part 1: Applications for individuals: a) distance and on-site education; $b$ ) library and information services. Part 2:

Applications for organizations: a) computer supported cooperative work; b) in-house training; c) managerial applications. Part 3 Applications for communities: a) rural and remote; b) gerontology; c)third world development; d) international communities of interest.

Valacich, J. S., Dennis, A. R. and Nunamaker Jr, J. F. (1991) "Electronic meeting support: The GroupSystems concept." Int J Man Machine Studies, 34(2), p262-282, February. In the special edition on CSCW \& Groupware. Republished in Greenberg, 1991.

(decision support, face-to-face meetings, evaluation) This paper highlight the theoretical assumptions 
behind the design of the University of Arizona's GroupSystem' face to face meeting room and its workings.. Of particular importance is that GroupSystems has been well-studied; fifteen experimental and field studies are summarize and contrasted here. The authors then provide recommendations for developers of electronic meeting rooms based upon the lessons learnt.

Vershkov, A. and Roussakov, A. (1989) "Cooperatives in the USSR." In Proceedings of the 1st European Conference on Computer Supported Cooperative Work (EC-CSCW'89), Gatwick, U.K., September 13-15, Computer Sciences House, Sloug, UK.

Vertelney, H. (1990) "An environment for collaboration." In The art of human-computer interface design, p161-170, B. Laurel ed., Reading, Massachusetts, Addison-Wesley.

(overview) The purpose of collaboration technology is to facilitate and enhance the daily work and interactions of people and machines bound together under the umbrella of a common goal, project, or job. This chapter looks at how work on complex projects gets accomplished, emphasizing the key components of communication, cooperation, and coordination of dispersed people. A working environment is envisioned where database, communications and userinterface technologies are sewn together to support the real activities of people involved in projects.

Victor, F. and Sommer, E. (1989) "Supporting the design of office procedures in the DOMINO system." In Proceedings of the 1st European Conference on Computer Supported Cooperative Work (EC-CSCW'89), Gatwick, U.K., September 13-15, Computer Sciences House, Sloug, UK.

Vogel, D. R. and Nunamaker, J. F. (1990) "Design and assesment of a group decision support system.” In Intellectual Teamwork: Social Foundations of Cooperative Work, p511-528, J. Galegher, R. E. Kraut and C. Egido ed., Hillsdale, New Jersey, Lawrence Erlbaum Associates. (decision support, face-to-face meetings) The design and use of the University of Arizona's Group Decision Support System is described. Included are the behavioural realm in which the system is intended to operate and users' reports about their experiences with the system.

Watabe, K., Sakata, S., Maeno, K., Fukuoka, H. and Ohmori, T. (1990) "Distributed multiparty desktop conferencing system: Mermaid." In Proceedings of the Conference on Computer Supported Cooperative Work (CSCW'90), p2738, Los Angeles, California, October 7-10, ACM Press. (remote meetings, shared workspace, video, evaluation) Mermaid is an ISDN-based distributed multiparty desktop conferencing system. Participants can interchange information through video, voice, and multimedia documents. The environment includes electronic writing pads, image scanners, video cameras, and microphone-installed loudspeakers. The system is evaluated informally for both performance and usability.

Watson, R. T., DeSanctis, G. and Poole, M. S. (1988) "Using a GDSS to facilitate group consensus: Some intended and unintended consequences." MIS Quarterly, 12(3), p463-478, September.

(decision support, evaluation) The study examines the effects of a group decision support system in resolving conflicts of personal preference. The three experimental conditions were: a computer-based support system; a manual, paper and pencil, support system; no support whatsoever. In general, the technology appeared to offer some advantage over no support, but little advantage over the pencil and paper method.

Weedman, J. (1991) "Task and non-task functions of a computer conference used in professional education: a measure of flexibility." Int J Man Machine Studies, 34(2), p303-318, March. In the special edition on CSCW \& Groupware. Republished in Greenberg, 1991.

(asynchronous conferencing, evaluation) What is computer-mediated communication used for? Some systems are based upon the assumption that communication is related to a specific task or action which can be captured and formalized (eg the Coordinator, Winograd, 1988). Weedman noticed that typical asynchronous computer communication also has a large non-task component used for such things as social exchange, expressing frustrations, and so on. She argues that since variety and vigour of communication is important to successful collaboration, the underlying technology should be flexible enough to support informal as well as formal talk.

White, G. M. (1990) “A formal method for specifying temporal properties of the multi-user interface." In Proceedings of IFIP WG8.4 Conference on Multi-User Interfaces and Applications, Crete, S. Gibbs and A. A. VerrighnStuart (ed), North Holland.

Whiteside, J. and Wixon, D. (1988) "Contextualism as a world view for the reformation of meetings." In Proceedings of the Conference on ComputerSupported Cooperative Work (CSCW'88), p369376, Portland, Oregon, September 26-28, ACM Press. (conceptual) Foundations for research and action in the area of group work are examined. Contextualism is discussed in depth.

Whittaker, S. (1991) “Coordinating activity: An analysis of interaction in computer supported cooperative work." In ACM SIGCHI Conference on Human Factors in Computing Systems, New Orleans, April 28-May 2, ACM Press. (evaluation)

Winograd, T. (1988a) "A language/action perspective on the design of cooperative work." Human Computer Interaction, 3(1), p3-30. Reprinted in 
Greif, 1988. An earlier version appeared in CSCW '86.

(protocols, semi-structured messages) This paper introduces a perspective based on language as action, and explores its consequences for practical system design. The language/action perspective is contrasted to a number of other currently prominent perspectives, andis illustrated with an extended example based on studies of nursing work in a hospital ward. The author shows how it leads to particular analyses of that work, which reveal potentails for creating new designs that can make the work (and the workers) more effective.

Winograd, T. (1988b) "Where the action is." Byte, December.

(semi-structured messages, protocols) This paper gives a simple description of speech acts and its basis behind the Coordinator. Sample screens from the Coordinator are shown along with its description.

Winograd, T. and Flores, F. (1986) Understanding computers and cognition: A new foundation for design, Ablex, Norwood, New Jersey. (conceptual, protocols, semi-structured messages) This book looks at the philosophy and theory of artificial intelligence and human cognition. Amongst other things, it looks at computer systems from the language/action perspective (speech acts).

Witten, I. H., Thimbleby, H. W., Coulouris, G. and Greenberg, S. (1991) "Liveware: A new approach to sharing data in social networks." Int J Man Machine Studies, 34(3), p337-348, March. In the special edition on CSCW \& Groupware.

Republished in Greenberg, 1991. (data sharing, implementation) A large part of a group process is information sharing. While networked computers usually allow people within an institution to share information across common data files, networks are rarely available for loosleycoupled social groups. This paper describes Liveware, a socially productive benign virus used to spread information across intermittently connected people and groups. Unlike conventional wired networks, Liveware is cheap, does not require a technical infrastructure, and is intrinsically intertwined with social convention of "casual" information sharing by mobile and flexible work groups.

Woitass, M. (1990) "Coordination of intelligent office agents - applied to meeting scheduling." In Proceedings of IFIP WG8.4 Conference on MultiUser Interfaces and Applications, Crete, S. Gibbs and A. A. Verrighn-Stuart (ed), North Holland.

Wright, K. (1990) "The road to the global village." Scientific American, p83-94, March. March. (overview, conceptual) This lay article speculates on the "global village" (Marshall MacLuhan's vision of an interconnected worldwide society) and how it may be brought about by the convergence of computing and communications technologies. Various humancomputer perspectives are reviewed by interview bites from familiar sources such as PARC, MIT Media Lab, etc. Technologies such as Multimedia, groupware, and Virtual Environments are also raised.
Wrycza, S. (1989) "The impact of CASE tools on teamwork of information systems developers." In Proceedings of the 1st European Conference on Computer Supported Cooperative Work (ECCSCW '89), Gatwick, U.K., September 13-15, Computer Sciences House, Sloug, UK.

Wulff, W., Evenson, S. and Rheinfrank, J. (1990) "Animating interfaces." In Proceedings of the Conference on Computer Supported Cooperative Work (CSCW '90), Los Angeles, California, October 7-10, ACM Press.

(software design) Requirements for prototyping tools in user interface and system design are discussed, and 'Animating Interfaces' is introduced as one collaborative, iterative approach to the rapid conceptual prototyping and simulation of interfaces and associated functionalities. The Animating Interfaces process is described, and illustrated by example.

Yakemovic, K. C. B. and Conklin, E. J. (1990) "Report on a development project use of an issuebased information system." In Proceedings of the Conference on Computer Supported Cooperative Work (CSCW '90), Los Angeles, California, October 7-10, ACM Press.

(semi-structured messages, protocols, decision support, hypertext) It has long been recognized that certain kinds of vital information--usually informal and unstructured, often having to do with why certain actions are taken--are usually lost in large projects. One explanation may be that this kind of information is too unstructured to be readily captured and retrieved. The paper reports a field study in which a simple structuring method called IBIS was used over a long time period to record and retrieve this kind of information, using very simple technology. Implications to hypertext and groupware are provided.

Yoder, E., Akscyn, R. and McCracken, D. (1989) "Collaboration in KMS, a shared hypermedia system." In Proceedings of the SIGCHI Human Factors in Computing Systems, p37-42, Austin, Texas, April 30-May 4, ACM Press.

(hypertext, data sharing) This paper describes how the KMS hypermedia system was used for collaborative work. Six fundamental issues were addressed via the shared-database capabilities of KMS and particular aspects of its data model. 